\title{
Sleep and dreaming are for important matters
}

\author{
L. Perogamvros ${ }^{1,2,3 *}$, T. T. Dang-Vu ${ }^{4}$, M. Desseilles ${ }^{5,6}$ and S. Schwartz ${ }^{2,3}$ \\ 1 Sleep Laboratory, Division of Neuropsychiatry, Department of Psychiatry, University Hospitals of Geneva, Geneva, Switzerland \\ ${ }^{2}$ Department of Neuroscience, University of Geneva, Geneva, Switzerland \\ ${ }^{3}$ Swiss Center for Affective Sciences, University of Geneva, Geneva, Switzerland \\ ${ }^{4}$ Department of Exercise Science, Center for Studies in Behavioral Neurobiology, Concordia University, Montreal, QC, Canada \\ ${ }^{5}$ Department of Psychology, University of Namur Medical School, Namur, Belgium \\ ${ }^{6}$ Alexian Brother Psychiatry Clinic, Henri-Chapelle, Belgium
}

\section{Edited by:}

Jennifer M. Windt, Johannes

Gutenberg-University of Mainz,

Germany

Reviewed by:

Erin J. Wamsley, Harvard Medical School, USA

Edward F. Pace-Schott, Harvard

Medical School, USA

*Correspondence:

L. Perogamvros, Sleep Laboratory,

Division of Neuropsychiatry,

Department of Psychiatry, University

Hospitals of Geneva, Chemin du

Petit-Bel-Air 2, 1225, Geneva

Switzerland

e-mail: lampros.perogamvros@

hcuge.ch
Recent studies in sleep and dreaming have described an activation of emotional and reward systems, as well as the processing of internal information during these states. Specifically, increased activity in the amygdala and across mesolimbic dopaminergic regions during REM sleep is likely to promote the consolidation of memory traces with high emotional/motivational value. Moreover, coordinated hippocampal-striatal replay during NREM sleep may contribute to the selective strengthening of memories for important events. In this review, we suggest that, via the activation of emotional/motivational circuits, sleep and dreaming may offer a neurobehavioral substrate for the offline reprocessing of emotions, associative learning, and exploratory behaviors, resulting in improved memory organization, waking emotion regulation, social skills, and creativity. Dysregulation of such motivational/emotional processes due to sleep disturbances (e.g., insomnia, sleep deprivation) would predispose to reward-related disorders, such as mood disorders, increased risk-taking and compulsive behaviors, and may have major health implications, especially in vulnerable populations.

\section{Keywords: sleep, dreaming, emotion, memory, learning, reward system, creativity}

\section{INTRODUCTION}

Sleep is a reversible condition of reduced responsiveness usually associated with immobility. All animal species present some form of sleep (or rest, which is considered as the sleep equivalent in reptiles, amphibians, fish, and invertebrates), and all need recovery sleep when staying awake longer than usual (i.e., increased sleep pressure) (Cirelli and Tononi, 2008). Sleep contributes to several basic physiological functions pertaining to immunity, hormonal regulation, thermoregulation, and ontogenesis, for example (Morrissey et al., 2004; Van Cauter et al., 2008; Opp, 2009). Conversely, sleep deprivation has deleterious consequences, like increased blood pressure, increased risk for diabetes, obesity, decrease of growth hormones (Van Cauter et al., 2008), and can even be fatal (e.g., in flies and rats) (Rechtschaffen and Bergmann, 2001; Cirelli and Tononi, 2008). Yet, cognitive and emotional disturbances may represent the most noticeable and immediate effects of sleep deprivation. Thus, sleep may serve essential neurological and psychological functions. Reactivation of circuits responsible for memory, emotion, and reward processing during sleep is consistent with this possibility. Indeed, in recent years, neuroimaging and neurophysiological studies

Abbreviations: ACC, anterior cingulate cortex; dlPFC, dorsolateral prefrontal cortex; HC, hippocampus; ML-DA, mesolimbic dopaminergic system; mPFC, medial prefrontal cortex; N1, N2, N3, stages N1, N2, and N3 of NREM sleep; NAcc, nucleus accumbens; NREM sleep, non-rapid-eye movement sleep; OFC, orbitofrontal cortex; PFC, prefrontal cortex; PPT, pendunculopontine tegmental nucleus; RAM, Reward Activation Model; REM sleep, rapid-eye movement sleep; SRED, sleep-related eating disorder; SWS, slow-wave sleep; TST, threat simulation theory; vmPFC, ventromedial prefrontal cortex; VS, ventral striatum; VTA, ventral tegmental area. have provided accumulating evidence of activated emotional and reward networks during sleep in both humans and animals (Maquet et al., 1996; Braun et al., 1997; Nofzinger et al., 1997; Lena et al., 2005; Dahan et al., 2007; Lansink et al., 2008). These activations seem to be related to the reprocessing and consolidation of memories with a high affective and motivational relevance for the organism (Perogamvros and Schwartz, 2012). Sleep would therefore promote adapted cognitive and emotional responses in the waking state, like performance improvement, emotional balance, and social cognition, among others (as will be discussed in detail below). Furthermore, reward activation in sleep is also supported by the overt expression of reward and emotional behaviors during sleep, as observed in some parasomnias, and by the fact that other sleep disturbances like insomnia and chronic sleep loss may contribute to the development of neuropsychiatric diseases, including mood disorders and addiction. We have proposed that the Reward Activation Model (RAM) may account for these seemingly disparate observations (Perogamvros and Schwartz, 2012).

Below, we ask how dreaming relates to the specific patterns of neural and behavioral activations observed during sleep, in particular whether dreaming may contribute to the offline reprocessing of emotions, associative learning, and exploratory behaviors. We first review existing evidence for the activation of emotional-limbic and reward-related circuits during sleep. We then describe the distinct consequences of such activations during sleep and dreaming for waking functions, including memory, emotions, social skills, and creativity. Because sleep supports essential emotional functions, sleep disturbances have intimate 
and complex relationships with neuropsychiatric illness, as we also discuss. We conclude by addressing the selectivity of neural and mental processes occurring during sleep, as opposed to those occurring during wakefulness.

\section{ACTIVATION OF EMOTIONAL AND REWARD CIRCUITS DURING SLEEP AND DREAMING}

Robust evidence for the activation of emotional and reward networks during sleep and dreaming comes from neuroimaging, neurophysiological, and behavioral studies in animals (Lena et al., 2005; Dahan et al., 2007) and humans (Maquet et al., 1996; Braun et al., 1997; Schenck and Mahowald, 2002; Cantero et al., 2003; Desseilles et al., 2011; Perogamvros et al., 2012). Lesion (Solms, 1997, 2000) and pharmacological (Gaillard and Moneme, 1977; Balon, 1996; Pinter et al., 1999; Thompson and Pierce, 1999) studies of dreaming as well as dream content analysis (Nielsen et al., 1991; Merritt et al., 1994; Malcolm-Smith et al., 2012) studies in humans also support such an implication of emotion and reward-related processes in dreams.

\section{NEUROIMAGING STUDIES IN HUMANS}

According to early neuroimaging studies, the distribution of brain activity during sleep is not homogeneous and is characterized by specific activation and deactivation patterns (e.g., Maquet et al., 1996; Braun et al., 1997; Nofzinger et al., 1997). More recent studies using imaging methods with higher temporal and/or spatial resolution (e.g., functional MRI, high-density EEG) reveal more transient changes in brain activity (e.g., Dang-Vu et al., 2008) and in brain connectivity (e.g., Massimini et al., 2005, 2010; Koike et al., 2011) across different sleep stages.

During NREM sleep, decreases in brain activity compared to wakefulness have been consistently found across multiple and distributed brain structures, in agreement with a homeostatic need for brain energy restorative processes. More specifically, decreases of brain perfusion and brain glucose metabolism in the brainstem, thalamus, basal ganglia, basal forebrain and across several cortical areas including the medial prefrontal cortex (mPFC) and precuneus have been demonstrated (Dang-Vu et al., 2010). However, more recent studies have revealed event-related increases of blood-oxygen-level-dependent (BOLD) responses within NREM sleep. In particular, NREM sleep spindles seem to be associated with increased BOLD responses in the lateral and posterior thalamus, as well as in emotion-related regions such as the anterior cingulate cortex (ACC), insula and superior temporal gyrus; in addition, fast spindles are associated with increased activity in the mPFC and hippocampus (HC) (Schabus et al., 2007). Slow waves on the other hand are associated with BOLD increases in the inferior frontal gyrus, brainstem, parahippocampal gyrus, precuneus and posterior cingulate cortex during NREM sleep (Dang-Vu et al., 2008). Finally, one preliminary study (14 subjects) demonstrated bilateral increases in regional glucose metabolism during the transition from waking to NREM in the ventral striatum (VS), anterior cingulate cortex, and extensive regions of the medial temporal lobe, including the amygdala and HC (Nofzinger et al., 2002).

During REM sleep, as compared to wakefulness, a first set of emotion-related regions are activated, including the HC, bilat- eral amygdala, and ACC (Maquet et al., 1996; Braun et al., 1997; Nofzinger et al., 1997). Amygdala, along with the brainstem, form interactions involved in cardiovascular regulation during sleep (Desseilles et al., 2006) and could reflect responses to intense emotions, in particular fear and anxiety, often experienced in dreams (Schwartz and Maquet, 2002; Smith et al., 2004). Amygdala connections with HC, thalamus, the septal nuclei, $\mathrm{mPFC}$ and ACC may also have an important role in strengthening affective value associated to memories (Sterpenich et al., 2007, 2009).

During REM sleep, several structures implicated in executive and attentional functions are significantly deactivated compared to the waking state, including the dorsolateral prefrontal cortex (dlPFC), orbitofrontal cortex (OFC), precuneus, and the inferior parietal cortex (Maquet et al., 1996, 2000, 2005; Braun et al., 1997; Nofzinger et al., 1997). Decreased brain perfusion and glucose metabolism in these regions may cause disorientation, illogical thinking, reduced cognitive control, and impaired working memory in dreaming (Hobson et al., 1998, 2000; Schwartz and Maquet, 2002; Schwartz, 2004; Pace-Schott, 2011).

\section{NEUROPHYSIOLOGICAL STUDIES}

Some key structures of the brain reward circuit, like the ventral tegmental area (VTA) and the nucleus accumbens (NAcc) are also activated during sleep (Solms, 2000; Perogamvros and Schwartz, 2012). In the context of the Reward Activation Model (RAM), we suggest that activation of this network of regions contributes to the reprocessing of memories with a high emotional or motivational relevance during sleep, in coordination with emotion-related circuits (Perogamvros and Schwartz, 2012). For example, during NREM sleep, a spontaneous reactivation (replay) of neuronal firing patterns occurs in VS neurons of rats after a reward searching behavior (Pennartz et al., 2004; Lansink et al., 2008). This off-line replay is induced by $\mathrm{HC}$ ripples and may be related to linking a memory trace to a motivational and emotional value during sleep (Lansink et al., 2009; Singer and Frank, 2009; Pennartz et al., 2011). In humans, HC and VS are also activated during NREM sleep (Nofzinger et al., 2002; Peigneux et al., 2004) (see above subsection Neuroimaging Studies). Note that it is unlikely (but still unclear) that the VTA significantly contributes to these processes occurring during NREM sleep, because activity of VTA neurons is relatively low during NREM sleep (Dahan et al., 2007). By contrast, VTA bursting activity is elevated during REM sleep of rats, up to levels observed during reward and punisher anticipation (Carter et al., 2009) and response to stimulus novelty (Bunzeck and Duzel, 2006; Wittmann et al., 2007; Krebs et al., 2011) at wake. Two studies have until now demonstrated that dopaminergic neurons in the VTA of rats express an increased bursting activity during REM sleep, inducing a large synaptic dopamine release in the nucleus accumbens (NAcc) shell (Maloney et al., 2002; Dahan et al., 2007). This activity is significantly higher in REM sleep compared to waking and to NREM and is comparable in intensity and duration to VTA activations during waking behaviors such as feeding, punishment, or sex (Dahan et al., 2007).

Activity in the NAcc is greatest when uncertainty about outcomes is maximal (Cooper and Knutson, 2008). It has been 
shown that there was an increase in extracellular levels of dopamine in the NAcc during REM sleep of rats (Lena et al., 2005). Other reward-related regions, like the ventromedial PFC (vmPFC) and the ACC, which assign a positive or negative value to future outcomes (Takenouchi et al., 1999; Bush et al., 2002; Haber and Knutson, 2010), are activated during REM sleep in humans (Maquet et al., 1996, 2000). In addition, the HC exhibits a theta rhythm during REM sleep in both animal (Winson, 1972; Popa et al., 2010) and human studies, although human theta activity may be more sporadic and of lower frequency compared to the theta in rodents (Cantero et al., 2003; Clemens et al., 2009). Increased theta oscillatory activity has been found in association with novelty-seeking, exploratory and instinctual behaviors (Panksepp, 1998), which are also overtly present in REM sleep behavior disorder and other parasomnias (Morrison et al., 1995; Jouvet, 1999; Perogamvros et al., 2012). Finally, the orexin neurons in the lateral hypothalamus, related to emotional processing and motivated behaviors (Harris et al., 2005; Schwartz et al., 2008; Ponz et al., 2010a,b; Thompson and Borgland, 2011), have occasional burst discharges during REM sleep of rodents (Mileykovskiy et al., 2005; Takahashi et al., 2008).

The neurophysiological evidence described above thus suggests that the mesolimbic-dopaminergic (ML-DA) reward and other instinctual exploratory motivational networks (SEEKING system) (Panksepp, 1998) are activated during sleep in mammals (Perogamvros and Schwartz, 2012). Figure 1 provides a plausible schema for the activation and functional interactions within the mesolimbic reward circuitry during NREM and REM sleep. This proposal is also inspired by recent models of hippocampal-VTA functions (Lisman and Grace, 2005).

\section{STUDIES OF PARASOMNIAS}

Parasomnias are sleep disorders that involve abnormal behaviors during sleep. Most parasomnias present dissociated sleep features, such as partial arousals during the transitions between wakefulness and NREM sleep (e.g. sleepwalking, confusional arousals, sleep terrors, sleep sex, sleep driving, sleep-related eating disorder, sleep violence), or during REM sleep (e.g., REM sleep behavior disorder, nightmares) (Howell, 2012). REM sleep behavior disorder typically occurs when there is a loss of normal muscle atonia during REM sleep resulting in overt motor behavior during dreaming (Schenck and Mahowald, 2002). It can be caused by adverse reactions to certain drugs or in neurodegenerative disorders such as Parkinson disease, multiple system atrophy, and Lewy Body Dementia. On the other hand, NREM parasomnias are characterized by a state dissociation, in which two states (wake, sleep) occur simultaneously (Bassetti et al., 2000). In addition, it has been proposed that inhibition of supraspinal influence on locomotor centers is an additional condition for NREM parasomnias to occur (Tassinari et al., 2005). While these mechanisms may explain motor disinhibition during the NREM or REM episode, the pathophysiological mechanisms underlying the specific variety of behaviors expressed during parasomnia episodes remain unresolved. In particular, exploratory and instinctual behaviors in humans are very frequently observed in parasomnias: oriented locomotion in sleepwalking, aggression in REM sleep behavior disorder, sexual behaviors in confusional arousals, and feeding, chewing, or swallowing in the sleep-related eating disorder (SRED) (Morrison et al., 1995; Shapiro et al., 2003; Vetrugno et al., 2006; Winkelman, 2006). These complex motor behaviors are most often characterized by negative affect (screaming,

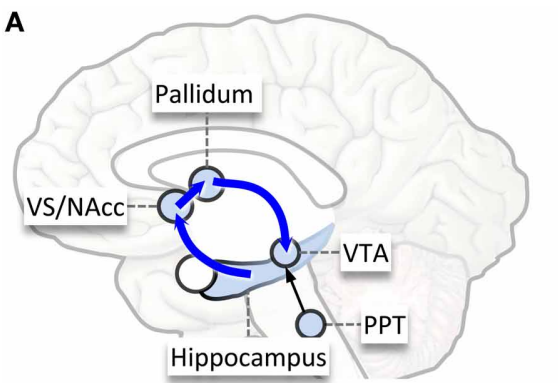

$\longrightarrow$ Downward arc of the
'hippocampal-VTA loop'

FIGURE 1 | Schematic illustration of the activation of the mesolimbic-dopaminergic reward system during sleep, and the possible functional interactions within this system, as proposed by the Reward Activation Model (RAM) (Perogamvros and Schwartz, 2012). (A) During NREM sleep, the activation between hippocampus and VS allows a spontaneous reactivation (replay) of reward-related neuronal firing patterns in the VS, which would involve a transfer of novelty/relevance signal from the hippocampus to the VTA (blue arrows). VTA would be activated during the transition from a NREM episode to REM sleep, with induction of both tonic (hippocampus-VTA projection) and phasic (PPT-VTA) increase of dopamine. Other emotion- and reward-related structures activated during NREM sleep

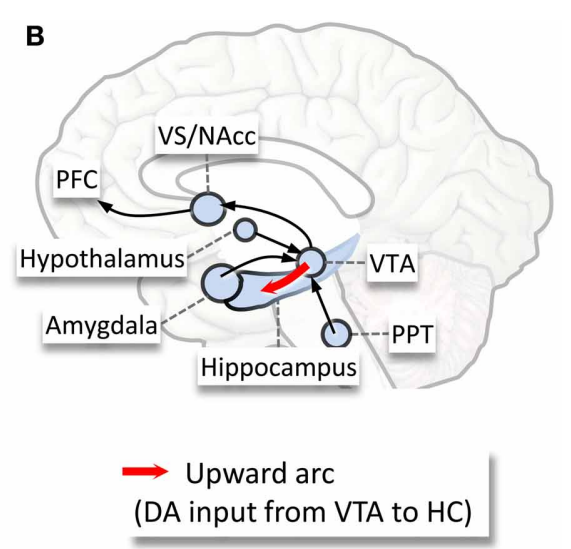

include the amygdala, the ACC and the insula. (B) During all REM sleep, increased bursting activity (phasic response) in the VTA may represent stimulus saliency and could fulfill reward-related functions, like acquisition of stimulus-reward associations, novelty-seeking and enhancement of learning procedures. During REM sleep, several VTA projections are activated, including the hippocampus (red arrow), the NAcc, the amygdala, the orexin/hypocretin neurons, the ACC, and the PFC. All these regions have strong anatomical and functional links with the hippocampus and VTA (among others). Abbreviations: ACC, anterior cingulate cortex; PFC, prefrontal cortex; PPT, penduculopontine tegmental nuclei; VS/NAcc, ventral striatum/nucleus accumbens; VTA, ventral tegmental area. Adapted from Perogamvros and Schwartz (2012). 
crying) (Oudiette et al., 2009), high motivational value (chewing, swallowing, and sexual behaviors), or even compulsive character (SRED, sleep- related smoking disorder) (Provini et al., 2008).

Preliminary data also support a positive correlation between individual daytime reward profile (e.g., novelty seeking, reward sensitivity) and motivational character of behavior during parasomnia episodes (Perogamvros et al., 2012) or in dreams (Johnson, 2001; Colace et al., 2010). The expression of reward networks in the form of overt behavior in sleep would thus require two concomitant conditions: (a) disinhibition of the central pattern generators of the spinal cord, a condition indispensable for parasomnias (Howell, 2012), and (b) elevated daytime exploratory approach, especially toward a certain kind of stimulus. Interestingly, many of the reward-related behaviors observed in parasomnias occur during N2 and N3 sleep stages (Howell, 2012). Moreover, motor and skill consolidation processes take place predominantly during NREM sleep (Walker et al., 2002a; Stickgold and Walker, 2007) and hippocampal ripples, which prevail during this sleep stage (coupled with the sleep spindles) (Clemens et al., 2011), have been implicated in learning and reward processes during sleep (Pennartz et al., 2004; Lansink et al., 2008).

\section{LESION, PHARMACOLOGICAL AND DREAM CONTENT ANALYSIS STUDIES}

Elevated dopamine level in the ML-DA system during sleep has been suggested to play an important role in the generation of dreams (Solms, 2000). Lesions in the white matter surrounding the frontal horns of the lateral ventricles can cause the cessation of dreaming in humans, without affecting REM sleep (Solms, 1997, 2000). These lesions typically disrupt the ML-DA connections from the VTA to the shell of the NAcc, amygdala, HC, ACC and frontal cortex (insular and medial OFC, medial frontal cortex, vmPFC) (Solms, 2000). This circuit corresponds to the mesolimbic circuits of the SEEKING system, which is a "curiosity-interest-expectancy" command system associated with instinctual appetitive craving states (Panksepp, 1998; Alcaro and Panksepp, 2011). It was thus proposed that the SEEKING system, a psychobehavioral emotional and motivational system subserving approach behaviors and emotional anticipation, is responsible for the generation of dreaming (Solms, 2000; Perogamvros and Schwartz, 2012). It should be noted that, while Panksepp's conceptualization is particularly suitable for addressing the role of the reward system in dreaming, it is compatible with other models of reward system such as those focusing on the reinforcementlearning functions of the reward system (Schultz, 2010a), the reward prediction error (Schultz, 1997, 2002; Redgrave et al., 1999; Schultz and Dickinson, 2000) or the 'incentive salience' (Berridge, 2007). Specifically regarding Berridge's model, "wanting" shares conceptual similarities with Panksepp's SEEKING system, as it corresponds to the organism's motivation, behavioral selection, and switching of attention toward reward-related stimuli and is associated mainly with dopaminergic signaling in mesolimbic structures (Berridge et al., 2009). Supplementary evidence that dreaming may be causally related to mesolimbic activation is sparse and mainly comes from pharmacological studies showing that the administration of dopaminergic agents in humans elicits vivid dreams (Balon, 1996; Pinter et al., 1999; Thompson and Pierce, 1999). On the other hand, administration of D2 antagonists is associated with a reduction in vivid dreaming (Gaillard and Moneme, 1977) and in nightmares (Jakovljevic et al., 2003; David et al., 2004; Lambert, 2006).

Most recent findings show that 'approach' behaviors in dreams are significantly more prevalent than 'avoidance' behaviors (Malcolm-Smith et al., 2012). Because approach implicates reward-related seeking brain mechanisms, these findings further support the hypothesis that reward-seeking mechanisms are activated during sleep. Importantly, the predominance of approach behaviors is not incompatible with the high prevalence of negative affect in dreams (Nielsen et al., 1991; Merritt et al., 1994; Revonsuo, 2000), because approach/avoidance behaviors and positive/negative emotions are independent psychological entities that engage partially dissociated brain circuits (mesolimbic dopaminergic system and amygdala-limbic system, respectively). For example, if the dreamer approaches an unknown place despite feeling scared, that is an instance of "approach" behavior coinciding with a negative affect (Malcolm-Smith et al., 2012). In any case, both approach and avoidance behaviors share the common feature of salience. Therefore, it seems that emotional, salience and stress networks, subserved by the fear expression (amygdala, ACC), mesolimbic (VTA, NAcc, vmPFC) and extrahypothalamic (extended amygdala) systems respectively, may collaborate or be in opposition during dreaming, according to the emotion/behavior/cognition characterizing each individual dreamed situation.

The "dopaminergic" theory of dreams, has been criticized by some authors (Hobson and Pace-Schott, 1999; Doricchi and Violani, 2000). Indeed, the influence of dopamine agonists or antagonists on dreaming may be partly mediated by a modulation of REM sleep states (Hobson and Pace-Schott, 1999). Moreover, lesions performed with leucotomy cited in Solms (Solms, 1997) may alter not only dopaminergic, but also cholinergic and noradrenergic efferent and afferent connections (Doricchi and Violani, 2000). Therefore, effects of dopamine on dreaming may be related to its interactions with other neuromodulatory systems, like basal forebrain cholinergic cells that activate cortical and limbic structures (Perry and Piggott, 2000). Besides, dream enhancement can also be observed in patients receiving a noradrenergic beta-receptor blocker (Thompson and Pierce, 1999) or cholinesterase inhibitors (Zadra, 1996). Consequently, interaction of dopaminergic with other neuromodulatory systems must be taken into consideration when studying the neurobiology of dreaming.

\section{ROLES OF ACTIVATION ACROSS EMOTIONAL/MOTIVATIONAL NETWORKS DURING SLEEP OFF-LINE MEMORY CONSOLIDATION}

One important function of sleep is memory consolidation, which can be regarded as an open-ended process by which new memories are progressively reorganized and incorporated into preexisting long-term memory networks (Wang and Morris, 2010). There is accumulating evidence that memory replay and consolidation processes may occur during both REM and NREM sleep in humans (Maquet, 2001; Stickgold, 2005; Diekelmann and 
Born, 2010; Oudiette and Paller, 2013). Both slow oscillations and sleep spindles during NREM sleep have been reported to be associated with memory (procedural and declarative) consolidation and synaptic plasticity processes (Huber et al., 2004; Rosanova and Ulrich, 2005; Marshall et al., 2006; Bergmann et al., 2008; Diekelmann and Born, 2010; Fogel and Smith, 2011). Besides, neuroimaging studies have demonstrated that both NREM and REM sleep may foster lasting neural changes as well as changes in functional connectivity after perceptual, motor, or emotional learning tasks (Schwartz et al., 2002; Maquet et al., 2003; Sterpenich et al., 2007; Payne and Kensinger, 2010).

On the one hand, activation of the HC and VS during NREM sleep may favor the replay of memory traces comprising contextual, emotional and motivational components (Lansink et al., 2009). Such coordinated reactivation of both HC and VS during NREM sleep provides a possible mechanism for the consolidation of associative memory-reward information (Lansink et al., 2009). In particular, the activation of reward-related neurons in the VS during NREM sleep seems important for selecting memories with a high storage priority (Lansink et al., 2008). Consistent with this hypothesis, declarative memory and skill consolidation observed during sleep is influenced by emotional relevance and motivational biases (Sterpenich et al., 2009; Wilhelm et al., 2011). Further evidence comes from a human study showing that NREM-dependent consolidation of motor skills can be enhanced when it is linked with an anticipation of reward (Fischer and Born, 2009) (but see Tucker et al., 2011). Specifically, NREMdependent improvement of a motor finger sequence was significantly greater when the sequence was associated with a future monetary reward. Another study demonstrated how such NREMspecific memory processes can be expressed in the form of an overt behavior in sleepwalking (Oudiette et al., 2011).

On the other hand, active memory processing could also explain the reward-related sustained bursting activity of the VTA (Dahan et al., 2007) and the increased dopamine in the NAcc (Lena et al., 2005) during REM sleep. The phasic VTA dopamine signals during REM sleep (Dahan et al., 2007) may favor an off-line replay of recent emotional memory traces during this sleep stage (Walker and Van Der Helm, 2009). These memories could then also serve as salient stimuli for VTA because the way that ML-DA neurons code for reward is strongly influenced by the individual's needs and relevant memories (e.g., emotional events, current concerns) (Schultz, 2010b). At the same time, memories could also engage the ML-DA system whenever they represent novel or unanticipated stimuli (Schultz and Dickinson, 2000), such as when they are activated in the absence of associated contextual information and/or of cognitive control from dlPFC during REM sleep (Fosse et al., 2003; Schwartz, 2003; PaceSchott, 2011). Importantly, memory and reward processes may form reciprocal relations, as ML-DA activation is necessary for memory formation and learning (Adcock et al., 2006; Shohamy and Adcock, 2010) (Figure 1B).

REM sleep was found to promote neuronal reorganization of emotional memory traces involving the progressive transfer of memories along a hippocampal-amygdalo-cortical route. More specifically, studies by Ribeiro and colleagues (Ribeiro et al., 2002; Ribeiro and Nicolelis, 2004) demonstrated an upregulation of the gene zif-268 [related to the expression of long-term potentiation, LTP (Richardson et al., 1992)] in the amygdala, entorhinal, auditory, somatosensory and motor cortices during REM sleep in rats. Further support for the role of REM sleep in LTP processes comes from studies showing that REM sleep deprivation negatively affects LTP in the visual cortex (Shaffery et al., 2002) and in the dorsal HC (Ravassard et al., 2009) of rats. In humans, functional MRI studies have found that REM-dependent enhanced functional connectivity between the amygdala and the mPFC subserve long-lasting consolidation of emotional memories (Sterpenich et al., 2009; Payne and Kensinger, 2011). Yet, despite robust limbic activation during REM sleep, the studies above suggest that all stages of sleep contribute to the consolidation of relevant memories (i.e., with an emotional or motivational value) involving substantial long-term reorganization within cerebral networks.

\section{EMOTIONAL REGULATION}

Both SWS and REM sleep have been linked to emotion regulation processes (Lara-Carrasco et al., 2009; Gujar et al., 2011a; Pace-Schott et al., 2011; Talamini et al., 2013). Several studies suggest that REM sleep may have a "depressiogenic" effect, and could possibly be deleterious for the emotional well-being. This idea comes from the observation that awakenings from an REM episode are characterized by an increased depressive score in the Hamilton Rating Scale for Depression (McNamara et al., 2010) and an enhanced aversive reactivity toward familiar affective stimuli (Wagner et al., 2002; Lara-Carrasco et al., 2009) [but see also (Gujar et al., 2011a; Van Der Helm et al., 2011)]. In addition, an increase in REM density and a reduced REM latency usually precede clinical depression, suggesting that REM sleep, which is under circadian and homeostatic control (Wurts and Edgar, 2000), may constitute a biomarker for depressive disease (Giles et al., 1998; Gottesmann and Gottesman, 2007).

In light of the recent findings on the consequences of total sleep deprivation and REM sleep deprivation on emotional and reward functions at the behavioral (Killgore et al., 2006; Banks and Dinges, 2007), neurobiological (Venkatraman et al., 2007; Yoo et al., 2007; Gujar et al., 2011b; Menz et al., 2012) and clinical (Riemann et al., 2002; Salvadore et al., 2010) levels, we propose here that REM sleep cannot be reduced to a depressiogenic sleep stage, but may instead have a crucial role in the maintenance of the integrity of emotional and reward networks. Indeed, perturbation of these networks with total or partial sleep deprivation leads to reduced disappointment in response to losses, together with decreased activity in the insular cortex (Venkatraman et al., 2007), which is thought to process the emotional significance of a stimulus, including the somatic affective response and awareness (Ernst and Paulus, 2005). Moreover, sleep deprivation caused attenuated conflict sensitivity for trials yielding high decision conflict (relatively large amounts associated with relatively low probability of winning) in a risky choice task, paralleled by a downregulation of conflict-related signals in the SN/VTA (Menz et al., 2012). A failure of top-down cortical control from the mPFC on the amygdala (Yoo et al., 2007), and an amplified reactivity of reward networks in response to positive emotional stimuli (Gujar et al., 2011b) have been also described as consequences of sleep deprivation. It has been also suggested that 
REM sleep may decrease the emotional reactivity to aversive or stressful experiences (Gujar et al., 2011a; Van Der Helm et al., 2011) (but see Pace-Schott et al., 2011; Talamini et al., 2013). Furthermore, changes in mood after sleep deprivation share several phenomenological similarities with hypomania, and the risk of hypomanic switch is elevated during and after sleep deprivation (Wehr et al., 1982; Colombo et al., 1999). Interestingly, antidepressants that do not suppress REM sleep (e.g., bupropion) (Nofzinger et al., 1995; Ott et al., 2004), have the least risk to induce a hypomanic switch in a depressed person (Leverich et al., 2006). This latter observation is consistent with the proposal that REM suppression is one of the main mechanisms by which most antidepressants and sleep deprivation induce hypomanic/manic symptoms (Salvadore et al., 2010). A subsensitization of presynaptic dopamine receptors (Tufik et al., 1987) and an increased noradrenergic tone (Payne et al., 2002) with REM sleep deprivation (compared with rested sleep) may be implicated in this effect. In sum, these results indicate that REM sleep fosters adapted emotional responses during waking life (Walker and Van Der Helm, 2009) by contributing to overnight emotional and reward brain functions.

The sustained activation of emotional and reward networks during dreams may also serve an emotion regulation function. Evidence in favor of this claim comes from the demonstration that mood in REM dreams improves over the course of a night sleep for subjects with pre-sleep depressed mood (Cartwright et al., 1998). This improvement may putatively be due to experiencing diverse emotional stimuli during dreaming; the exposure to feared stimuli (objects, situations, thoughts, memories, and physical sensations) in a totally safe context during dreaming may thus resemble desensitization therapy (Perlis and Nielsen, 1993; Levin and Nielsen, 2007). Furthermore, sleep was found to promote the retention and generalization of extinction learning, which could potentially be helpful in generalizing therapeutic extinction learning in exposure therapy (Pace-Schott et al., 2009, 2012b). Experiencing negative emotions during dreaming may thus function as a threat simulation system, which ultimately affords adapted emotional responses during waking life (Revonsuo, 2000). Nightmares would by contrast reflect the failure of fear memory extinction, in the presence of temporary (e.g., daily concerns) or more persistent (e.g., trauma) increases in affect load (Nielsen and Levin, 2007). Different REM dream characteristics have been found to relate to distinct facets of daytime affective functioning, such as suicide probability (i.e., frequency of nightmares) (Agargun et al., 2007), protection against depression after divorce (i.e., incorporation of marital status issues) (Cartwright et al., 1984), and response to antidepressant treatment (i.e., reduction of negatively toned dreams) (Schredl et al., 2009).

Extending the Threat Simulation Theory (TST) according to which dreaming allows an offline simulation of threatening events that promotes efficient threat-avoidance skills during wakefulness (Revonsuo, 2000), the Reward Activation Model (RAM) supports that dreaming (and offline processes during sleep) exposes the dreamer to memory and emotional content with a high storage priority, for example relating to instinctual behaviors or drives (such as feeding, mating, fighting, fleeing, etc.), as well as to novel internally-generated stimuli (e.g., original combinations of elements from memory) (Perogamvros and Schwartz, 2012). Based on robust neurophysiological evidence of reward activation during sleep, the RAM thus implies that dreams do not only relate to known past events but also to an unexpected, novel or probabilistic future (see also Perogamvros and Schwartz, 2012; Pace-Schott, 2013). Further supporting this hypothesis, dream content analysis has shown that although past and current waking concerns are common in dreams (Schredl and Hofmann, 2003; Cartwright et al., 2006), dreams are usually novel constructions and rarely reproductions of past events (Fosse et al., 2003; Schwartz, 2003).

While mental activity during REM and NREM sleep vary across the night sleep, with NREM dreams becoming longer, less thought-like and more dream-like and bizarre, thus resembling REM dreams in the morning (Fosse et al., 2004; Wamsley et al., 2007a), dream content analyses report generally higher emotional intensity in REM than in NREM dreams (Smith et al., 2004; McNamara et al., 2005; Wamsley et al., 2007a), consistent with the robust activation of limbic structures during REM sleep. On the other hand, dreamer-initiated friendliness is frequent in NREM dreams, while aggressive social interactions may be more characteristic of REM reports (McNamara et al., 2005). Dream data thus confirm that emotional and motivational processes may be active during both REM and NREM sleep stages, in line with the present proposal (section Activation of Emotional and Reward Circuits During Sleep and Dreaming). However, they also suggest that some types of emotional experience may prevail during specific sleep stages, with more intense negative emotions and aggressiveness possibly predominating in REM dreams.

\section{THEORY OF MIND IN DREAMS}

The reprocessing and consolidation of memories with a high affective or motivational relevance for the organism may prioritize both social cognition and self-representation processes during dreaming. Accordingly, it has been proposed that our ability to attribute mental states to self and others (i.e., theory of mind) may be at least partly preserved in dreams (Pace-Schott, 2001, 2007; Kahn and Hobson, 2005; McNamara et al., 2005). Envy, embarrassment, attachment, sexual attraction, shame, pride, etc. are often reported in dreams, thus supporting the idea that the dreamer is exposed to both his/her own emotions and the expression of emotions in other dream characters. Moreover, social interactions as well as attribution of mental states to dream characters appear to be controlled by NREM and REM mechanisms: NREM dreaming would predominantly simulate friendly interactions, self-related information, and actual waking life events, whereas REM dreams contain comparatively more aggressive social interactions (McNamara et al., 2005) and less integration between self-referential and social cognitive reasoning with autobiographical memory (Pace-Schott, 2013). This dissociation fits the more general finding that the expression of instinctual emotions and behaviors (e.g. fear and aggressiveness) is more prevalent in REM than NREM dreams (Smith et al., 2004; Wamsley et al., 2007b), which in turn is consistent with substantially larger activation of the amygdala and other limbic regions in REM relative to NREM sleep (Vandekerckhove and Cluydts, 2010). 
Pace-Schott has recently proposed that the activation of the brain's "default network" during sleep may help explain the expression of social skills and affects during NREM and REM sleep (Pace-Schott, 2007, 2013) (see also Domhoff, 2011). The default-mode network encompasses a set of connected brain regions that are thought to be typically activated when individuals are engaged in internally-focused tasks including spontaneous cognition, daydreaming, autobiographical memory retrieval, imagination, and introspection (Buckner et al., 2008). Two main default-network subsystems have been identified: the dorsomedial prefrontal subsystem (dorsomedial prefrontal cortex, lateral temporal cortex, temporoparietal junction and temporal pole), which is selectively activated during self-reflection and attribution of mental states to others, and the medial temporal subsystem (hippocampus-parahippocampus, retrospenial cortex and vmPFC), which is activated during memory retrieval and prospective memory (Buckner et al., 2008; Andrews-Hanna, 2012). While correlations among brain regions of the defaultmode network largely persist during N1 and N2 stages of NREM sleep (Laufs et al., 2007; Horovitz et al., 2008; Larson-Prior et al., 2009), there is evidence for reduced frontal connectivity during SWS (Horovitz et al., 2009; Samann et al., 2011) and reduced connectivity within the dorsomedial prefrontal subsystem during REM sleep (Koike et al., 2011). In addition, mPFC and most of the medial temporal lobe subsystem seem activated during REM sleep (Pace-Schott, 2013). These temporal, stage-dependent changes in the connectivity of components of the default-network may explain the distinct roles of NREM and REM stages in the expression of self-reflection, social skills and the "mentalizing" function of sleep. Whether this constitutes a mechanism by which dreams facilitates the resolution of social and emotional conflicts remains to be addressed in future studies (Desseilles et al., 2011).

\section{CREATIVITY}

There are innumerous anecdotal accounts suggesting that sleep enhances creativity and problem solving in artists and scientists. It is said that Robert Louis Stevenson came up with the plot of Strange Case of Dr Jekyll and Mr Hyde during a dream, and that Mary Shelley's Frankenstein was also inspired by a dream at Lord Byron's villa. Paul McCartney purportedly discovered the tune for the song "Yesterday" in a dream and was inspired to write "Yellow Submarine" after hypnagogic auditory hallucinations. Otto Loewi (1873-1961), a German-born physiologist, dreamed of the experiment that ultimately allowed him to prove chemical synaptic transmission, and was later awarded the Nobel Prize. In one of the first experimental studies addressing the relation between sleep and creativity (Home, 1988), participants either underwent $32 \mathrm{~h}$ of sleep deprivation or slept normally. The sleep-deprived participants scored low on measures of cognitive flexibility and originality, suggesting that sleep deprivation impairs divergent thinking. More recently, Walker et al. (2002b) demonstrated that subjects awoken after REM sleep had a 32\% advantage on an anagram solving task, compared with the number of correct responses after NREM awakenings. In a similar study, (Stickgold et al., 1999) used a semantic priming task and elegantly demonstrated that subjects awoken from REM sleep showed greater priming by weak primes (than by both unrelated primes and strong primes), consistent with a hyperassociative state of the sleeping mind, as also observed in REM dreams. More recently, Cai et al. (2009) showed that compared with quiet rest and non-REM sleep, REM sleep enhances the integration of initially unassociated information resulting in more creative problem solving. In addition, sleep can also facilitate insightful behavior because it involves a restructuration of new memory representations (Wagner et al., 2004; Pace-Schott et al., 2012a).

Activation of the dopaminergic system during sleep likely underlies some of these findings. Indeed, an important function of the dopaminergic system is to favor creativity, including associative thinking, innovative insights, cognitive flexibility and divergent thinking (Akbari Chermahini and Hommel, 2010). Further evidence comes from Parkinson's disease patients under dopaminergic treatment, who may develop increased artistic drive and productivity (Inzelberg, 2013). Moreover, spontaneous creative activity, like in jazz improvisation, has been linked to absence of control from structures that typically mediate conscious volitional control of ongoing performance, like the dlPFC, and simultaneous activation of internally motivated, stimulus-independent behaviors, subserved by the mPFC (Limb and Braun, 2008). Interestingly, dlPFC is deactivated and the mPFC is activated during REM sleep (Maquet et al., 1996), supporting the specific potential role of this sleep stage in human creativity.

\section{CAN SLEEP DISTURBANCES PRECIPITATE NEUROPSYCHIATRIC DISEASE?}

In the previous section (section Roles of Activation across Emotional/Motivational Networks during Sleep), we showed that sleep and dreaming may have an impact on various aspects of waking cognitive functions (memory consolidation, emotional regulation, self and others representations, and creativity). Yet, any claim about causal relations between sleep and these functions would require further research and considerations. Indeed, physiological parameters other than those related to specific sleep stages, such as circadian processes (circadian phase), homeostatic processes (duration of prior wakefulness) (Boivin et al., 1997), or others, could be responsible for such modulations. It is true that even a minimal misalignment between circadian phase and sleep phase can deteriorate mood (Danilenko et al., 2003), potentially explaining mood-related problems (e.g., irritability) in jet-lag or shift work (Kolla and Auger, 2011), and severity of unipolar depression (Hasler et al., 2010). In addition, mood deteriorates with increased duration of prior wakefulness (Boivin et al., 1997). Thus, we could as well hypothesize that insomnia (i.e., the subjective perception of inadequate sleep) or sleep loss (an objective measure of sleep reduction) does not affect daytime functioning. Below, we provide cases against this statement.

\section{SLEEP DISTURBANCES AND MOOD DISORDERS}

Sleep deprivation is an objectively measured decrement in sleep, which often has an immediate antidepressant effect in depressed patients (Barbini et al., 1998; Giedke and Schwarzler, 2002). Usually this effect is short-lived, with $50-80 \%$ of the responders relapsing after recovery sleep (Giedke and Schwarzler, 2002). 
Several hypotheses have been formulated to explain this antidepressant effect, including dopaminergic (Ebert and Berger, 1998), noradrenergic (Payne et al., 2002), circadian (Wehr and WirzJustice, 1981), and homeostatic (Endo et al., 1997) mechanisms. On the other hand, insomnia is a subjective perception of inadequate sleep that represents an independent major risk of subsequent onset of major depression (Ford and Kamerow, 1989; Riemann and Voderholzer, 2003; Johnson et al., 2006; Buysse et al., 2008; Roane and Taylor, 2008). Hypomania and mania have also been causally linked to reduced need for sleep (Wehr et al., 1987; Wehr, 1991; Plante and Winkelman, 2008). Indeed, a decrease in sleep may trigger a shift toward hypomania/mania in bipolar patients, whereas an increase in sleep can lead to a shift toward depression (Bauer et al., 2006). In addition, sleep disturbances are the most common prodrome of mania and the sixth most common prodrome of depression (Jackson et al., 2003).

Which neurophysiological mechanisms may explain such functional links between sleep disturbances and mood disorders? As depression is also considered as a risk factor for insomnia (Ohayon and Roth, 2003), it has been proposed that the reciprocal links between mood disorders/sleep disturbances form a closed loop (Harvey, 2008). Circadian (Wirz-Justice, 2003; Roybal et al., 2007; Li et al., 2013) and neuroendocrine (Schmider et al., 1995; Spiegel et al., 1999; Holsboer, 2000) mechanisms may partially, but not totally subserve a direct causality between sleep disturbances and mood disorders. Activation of emotional and reward networks during sleep as proposed here may offer a supplementary and necessary mechanism. Indeed, conditions of chronically disrupted sleep, like in insomnia or chronic sleep deprivation, are known to produce reward-related and memoryrelated deficits, such as deficits in working memory, episodic memory and executive functioning (Van Dongen et al., 2003; Fortier-Brochu et al., 2012), decreased global emotional intelligence, empathy toward others and quality of interpersonal relationships (Killgore et al., 2008), increased aggressiveness (Kamphuis et al., 2012), and negative mood states (Dinges et al., 1997; Zohar et al., 2005). Impaired overnight consolidation of declarative memory is also observed in patients with primary insomnia (Backhaus et al., 2006). In addition, chronic insomnia is characterized by structural abnormalities of reward-related and memory-related structures such as the OFC (Altena et al., 2010), the HC (Riemann et al., 2007), and the ACC (Plante et al., 2012). Cumulative functional deficits in the integrity of emotional and reward networks because of sleep deprivation (as presented in the subsection Emotional Regulation) may also add to chronic structural abnormalities. Similar reward-related deficits, such as decreases in the capacity to seek out rewards, in decision-making (aboulia), and in the ability to experience pleasure (anhedonia), are also characteristics of depression (DerAvakian and Markou, 2012), and depict a dysfunction across mesolimbic and non-mesolimbic reward networks (Tremblay et al., 2005; Pizzagalli et al., 2009; Blood et al., 2010). In addition, reward dysfunction in hypomania/mania, at both the neurophysiological (Blumberg et al., 2000; Rubinsztein et al., 2001; Abler et al., 2008) and the phenomenological (increased risk taking, impulsivity) (Mason et al., 2012) levels, is also observed.
Taking into consideration such deficits in both insomnia and mood disorders, we propose that sleep disturbances may be causally related to mood disorders, notably by altering reward processing in a way that would precipitate the reward-deficient symptomatology found in depression/mania. Future studies are needed to clarify if specific characteristics of sleep restrictions (in microstructure, macrostructure, duration or quality of sleep) predict specific manic or depressive symptoms. It should be also noted that, as already mentioned, unipolar depression or bipolar disorder cannot be reduced only to a consequence of sleep disturbances and reward-related deficits, as their pathophysiology is characterized by complex interactions between genetic, biological, psychological and social determinants.

\section{SLEEP DISTURBANCES AND COMPULSIVITY}

Compulsive behaviors like drug addictions are characterized by an inability to reduce the occurrence of an approach behavior toward a primary or secondary reward (e.g., food, drug), and by a negative emotional state when the access to the reward is precluded. It is now well-established that compulsive behaviors may relate to a dysregulation of the hedonic (OFC, insula), emotional (amygdala), and motivational (VTA, NAcc) components of the reward networks (Koob, 2009; Koob and Volkow, 2010). Recent findings suggest that sleep disturbances like insomnia, sleep deprivation and circadian misalignment may developmentally precede and predict early onset of alcohol, cigarette and marijuana use in adolescents and young adults (Roane and Taylor, 2008; Wong et al., 2009; Hasler and Clark, 2013). A disruption of brain reward networks, as well as ineffective emotion regulation processes due to sleep disturbances, could explain the compensatory drug and food seeking in sleep deprived animals (Puhl et al., 2009) and humans (Benedict et al., 2012; Telzer et al., 2013). Disturbances of neuroendocrine (Van Cauter et al., 2008) mechanisms may also be implicated in these interactions. Conversely, sustained cocaine abstinence was shown to cause symptoms of chronic insomnia that may increase the probability for future relapse (Morgan et al., 2006). Future longitudinal studies would be useful to further substantiate and clarify these links between sleep disturbances and compulsive behaviors.

\section{SLEEP AND DREAMING: WHAT THE WAKING STATE CANNOT OFFER}

We have provided evidence supporting that both REM and NREM sleep may offer a neurobehavioral substrate for offline reprocessing of emotion or associative learning (section Roles of Activation across Emotional/Motivational Networks during Sleep). In particular, we suggest that by critically supporting learning and memory processes, sleep may influence the development and maintenance of waking consciousness (Hobson, 2009; Hobson and Friston, 2012). In addition, sleep disturbances may trigger waking state neuropsychiatric disorders (section Can Sleep Disturbances Precipitate Neuropsychiatric Disease?). Importantly, sleep seems to serve primordial neural and cognitive functions that cannot be provided by wakefulness (Cirelli and Tononi, 2008). Specifically, the neural traces coding for newly acquired information are reactivated during subsequent periods of both SWS and/or REM sleep, thus leading to 
enhancement of memory performance in waking (Maquet et al., 2000; Maquet, 2001; Stickgold, 2005; Rasch et al., 2007; Rudoy et al., 2009; Diekelmann and Born, 2010; Oudiette and Paller, 2013). Reactivation of organized sequences of behavior in humans are also supported by the report that trained motor sequences are replayed in the form of overt behavior in patients with parasomnia (Oudiette et al., 2011). It has been shown that memories are destabilized during waking memory reactivation (being thus vulnerable to interference), but stabilized by memory reactivation occurring during SWS (Diekelmann et al., 2011). Moreover, recent experimental evidence also demonstrated that, after training on a virtual navigation task, reactivation of taskrelated mentation in dreams improved performance, and significantly more than when task-related thoughts occurred during wakefulness (Wamsley et al., 2010). Together, these findings support the existence of learning and memory processes that are specific to the sleep and dream states, thus making them important for waking performance.

Distinct sleep stages and dream states (associated with NREM or REM sleep) may also differ in their contribution to off-line reprocessing of emotional and reward information. NREM sleep may be more specialized in linking memory traces with motivational values (Pennartz et al., 2004; Lansink et al., 2009), whereas REM sleep is responsible for emotional memory consolidation, and synaptic consolidation (Wagner et al., 2001; Sterpenich et al., 2009; Diekelmann and Born, 2010; Popa et al., 2010; Payne and Kensinger, 2011). Whether REM and NREM dreams reflect distinct facets of sleep-dependent memory consolidation is unclear, and this is partly due to the fact that studies combining dream content analysis with an assessment of emotion and/or memory functions are scarce (Cartwright et al., 1998; Agargun et al., 2007; Wamsley et al., 2010). Hence, whether and how conscious experience in dreams causally contributes to the functions discussed in this article (i.e., memory consolidation, emotional regulation, associative learning, and creativity) remains hypothetical. Moreover, due to the specific brain states (i.e., REM and NREM sleep) in which dreaming occurs and the reduced sensory and contextual anchoring of the dream elements, memory for dreams is often poor as compared to everyday life memories (e.g., Schwartz and Maquet, 2002). While it is tempting to relate some aspects of dreaming to cognitive and emotional functions, as we do in this review and as others have done in

\section{REFERENCES}

Abler, B., Greenhouse, I., Ongur, D., Walter, H., and Heckers, S. (2008). Abnormal reward system activation in mania. Neuropsychopharmacology 33, 2217-2227. doi: 10.1038/sj.npp. 1301620

Adcock, R. A., Thangavel, A., Whitfield-Gabrieli, S., Knutson, B., and Gabrieli, J. D. (2006). Rewardmotivated learning: mesolimbic activation precedes memory formation. Neuron 50, 507-517. doi: 10.1016/j.neuron.2006.03.036

Agargun, M. Y., Besiroglu, L., Cilli, A. S., Gulec, M., Aydin, A., Inci,

the past (Threat Simulation Theory (Revonsuo, 2000), protoconsciousness theory (Hobson, 2009), default-mode activation theory (Pace-Schott, 2007; Domhoff, 2011), reward activation theory (Solms, 2000; Perogamvros and Schwartz, 2012), we need to acknowledge that data is still lacking in this domain to support any strong conclusions. Methodological improvements in the integration of self-report data with neuroimaging data represent a promising avenue for future developments in the science of dreaming (Horikawa et al., 2013; Perogamvros, 2013).

\section{CONCLUSIONS}

There is robust evidence supporting the activation of limbic, paralimbic and reward structures during NREM and REM sleep. These activations subserve important high-level cognitive functions, such as memory consolidation, emotional regulation processes, theory of mind, and creativity. Thus, waking consciousness is at least partly shaped by neural and mental processes occurring during sleep and dreaming. The contribution of sleep and dreaming to some specific functions (e.g., those pertaining to memory consolidation and creativity) appears to be unique, dissociated from similar processes occurring during wakefulness, and associated to specific sleep stages and possibly dream states. Some other functions, such as emotional regulation and social cognition, may benefit from dreaming, as this can provide an offline, virtual and safe environment, in which the dreamer can be exposed to an important load of rewarding or aversive stimuli. More empirical studies are needed to better characterize the potential roles of dreaming. Conversely sleep disturbances, such as insomnia and sleep deprivation, result in emotional distress and rewardrelated dysfunction, as frequently found in mood disorders and addiction. Future longitudinal studies could be useful to further substantiate and clarify these links. By presenting converging lines of evidence supporting the role of sleep in learning and emotion regulation, one of our goals would also be to encourage the development of preventive measures for populations, like children and psychiatric patients, who may be particularly vulnerable to the deleterious consequences of sleep loss.

\section{ACKNOWLEDGMENTS}

This work is supported by grants from the Swiss National Science Foundation, the Swiss Center for Affective Sciences, and the Boninchi Foundation.

neuro-affective substrates for appetitive incentive states and their pathological dynamics in addictions and depression. Neurosci. Biobehav. Rev. 35, 1805-1820. doi: 10.1016/j.neubiorev.2011.03.002

Altena, E., Vrenken, H., Van Der Werf, Y. D., Van Den Heuvel, O. A., and Van Someren, E. J. (2010). Reduced orbitofrontal and parietal gray matter in chronic insomnia: a voxel-based morphometric study. Biol. Psychiatry 67, 182-185. doi: 10.1016/j.biopsych.2009.08.003

Andrews-Hanna, J. R. (2012). The brain's default network and its adaptive role in internal mentation. Neuroscientist 18, 251-270. doi: 10.1177/1073858411403316

Backhaus, J., Junghanns, K., Born, J., Hohaus, K., Faasch, F., and Hohagen, F. (2006). Impaired declarative memory consolidation during sleep in patients with primary insomnia: influence of sleep architecture and nocturnal cortisol release. Biol. Psychiatry 60, 1324-1330. doi: 10.1016/j.biopsych.2006.03.051

Balon, R. (1996). Bupropion and nightmares. Am. J. Psychiatry 153, 579-580. 
Banks, S., and Dinges, D. F. (2007). Behavioral and physiological consequences of sleep restriction. J. Clin. Sleep Med. 3, 519-528.

Barbini, B., Colombo, C., Benedetti, F., Campori, E., Bellodi, L., and Smeraldi, E. (1998). The unipolar-bipolar dichotomy and the response to sleep deprivation. Psychiatry Res. 79, 43-50. doi: 10.1016/S0165-1781(98)00020-1

Bassetti, C., Vella, S., Donati, F., Wielepp, P., and Weder, B. (2000). SPECT during sleepwalking. Lancet 356, 484-485. doi: 10.1016/S0140-6736(00)02561-7

Bauer, M., Grof, P., Rasgon, N., Bschor, T., Glenn, T., and Whybrow, P. C. (2006). Temporal relation between sleep and mood in patients with bipolar disorder. Bipolar Disord. 8, 160-167. doi: 10.1111/j.13995618.2006.00294.x

Benedict, C., Brooks, S. J., O'Daly, O. G., Almen, M. S., Morell, A., Aberg, K., et al. (2012). Acute sleep deprivation enhances the brain's response to hedonic food stimuli: an fMRI study. J. Clin. Endocrinol. Metab. 97, E443-E447. doi: 10.1210/jc.20112759

Bergmann, T. O., Molle, M., Marshall, L., Kaya-Yildiz, L., Born, J., and Roman Siebner, H. (2008). A local signature of LTP- and LTD-like plasticity in human NREM sleep. Eur. J. Neurosci. 27, 2241-2249. doi: 10.1111/j.1460-9568.2008.06178.x

Berridge, K. C. (2007). The debate over dopamine's role in reward: the case for incentive salience. Psychopharmacology 191, 391-431. doi: 10.1007/s00213-006-0578-x

Berridge, K. C., Robinson, T. E., and Aldridge, J. W. (2009). Dissecting components of reward: 'liking', 'wanting', and learning. Curr. Opin. Pharmacol. 9, 65-73. doi: 10.1016/j.coph.2008.12.014

Blood, A. J., Iosifescu, D. V., Makris, N., Perlis, R. H., Kennedy, D. N., Dougherty, D. D., et al. (2010). Microstructural abnormalities in subcortical reward circuitry of subjects with major depressive disorder. PLOS ONE 5:e13945. doi: 10.1371/journal.pone.0013945

Blumberg, H. P., Stern, E., Martinez, D., Ricketts, S., De Asis, J., White, T., et al. (2000). Increased anterior cingulate and caudate activity in bipolar mania. Biol. Psychiatry 48, 1045-1052. doi: 10.1016/S00063223(00)00962-8

Boivin, D. B., Czeisler, C. A., Dijk, D. J., Duffy, J. F., Folkard, S., Minors, D. S., et al. (1997). Complex interaction of the sleepwake cycle and circadian phase modulates mood in healthy subjects. Arch. Gen. Psychiatry 54, 145-152. doi: 10.1001/archpsyc.1997.01830140055010

Borbely, A. A., and Wirz-Justice, A. (1982). Sleep, sleep deprivation and depression. A hypothesis derived from a model of sleep regulation. Hum. Neurobiol. 1, 205-210.

Braun, A. R., Balkin, T. J., Wesenten, N. J., Carson, R. E., Varga, M., Baldwin, P., et al. (1997). Regional cerebral blood flow throughout the sleepwake cycle. An H2(15)O PET study. Brain 120(Pt 7), 1173-1197. doi: 10.1093/brain/120.7.1173

Buckner, R. L., Andrews-Hanna, J. R., and Schacter, D. L. (2008). The brain's default network: anatomy, function, and relevance to disease. Ann. N.Y. Acad. Sci. 1124, 1-38. doi: 10.1196/annals.1440.011

Bunzeck, N., and Duzel, E. (2006). Absolute coding of stimulus novelty in the human substantia nigra/VTA. Neuron 51, 369-379. doi: 10.1016/j.neuron.2006.06.021

Bush, G., Vogt, B. A., Holmes, J., Dale, A. M., Greve, D., Jenike, M. A., et al. (2002). Dorsal anterior cingulate cortex: a role in rewardbased decision making. Proc. Natl. Acad. Sci. U.S.A. 99, 523-528. doi: 10.1073/pnas.012470999

Buysse, D. J., Angst, J., Gamma, A., Ajdacic, V., Eich, D., and Rossler, W. (2008). Prevalence, course, and comorbidity of insomnia and depression in young adults. Sleep 31, 473-480.

Cai, D. J., Mednick, S. A., Harrison, E. M., Kanady, J. C., and Mednick, S. C. (2009). REM, not incubation, improves creativity by priming associative networks. Proc. Natl. Acad. Sci. U.S.A. 106, 10130-10134. doi: 10.1073/pnas.0900271106

Cantero, J. L., Atienza, M., Stickgold, R., Kahana, M. J., Madsen, J. R., and Kocsis, B. (2003). Sleepdependent theta oscillations in the human hippocampus and neocortex. J. Neurosci. 23, 10897-10903.

Carter, R. M., Macinnes, J. J., Huettel, S. A., and Adcock, R. A. (2009). Activation in the VTA and nucleus accumbens increases in anticipation of both gains and losses. Front. Behav. Neurosci. 3:21. doi: 10.3389/neuro.08.021.2009

Cartwright, R., Agargun, M. Y., Kirkby, J., and Friedman, J. K. (2006). Relation of dreams to waking concerns. Psychiatry Res. 141, 261-270. doi: 10.1016/j.psychres.2005.05.013

Cartwright, R., Luten, A., Young, M., Mercer, P., and Bears, M. (1998). Role of REM sleep and dream affect in overnight mood regulation: a study of normal volunteers. Psychiatry Res. 81, 1-8. doi 10.1016/S0165-1781(98)00089-4

Cartwright, R. D., Lloyd, S., Knight, S., and Trenholme, I. (1984). Broken dreams: a study of the effects of divorce and depression on dream content. Psychiatry 47, 251-259.

Cirelli, C., and Tononi, G. (2008). Is sleep essential? PLoS Biol. 6:e216. doi: 10.1371/journal.pbio.0060216

Clemens, Z., Molle, M., Eross, L., Jakus, R., Rasonyi, G., Halasz, P., et al. (2011). Fine-tuned coupling between human parahippocampal ripples and sleep spindles. Eur. J. Neurosci. 33, 511-520. doi: 10.1111/j.1460-9568.2010.07505.x

Clemens, Z., Weiss, B., Szucs, A., Eross, L., Rasonyi, G., and Halasz, P. (2009). Phase coupling between rhythmic slow activity and gamma characterizes mesiotemporal rapideye-movement sleep in humans. Neuroscience 163, 388-396. doi: 10.1016/j.neuroscience.2009.06.044

Colace, C., Claps, M., Antognoli, A., Sperandio, R., Sardi, D., and Benedetti, A. (2010). Limbic system activity and drug dreaming in drug-addicted subjects. Neuropsychoanalysis 12, 201-206.

Colombo, C., Benedetti, F., Barbini, B., Campori, E., and Smeraldi, E. (1999). Rate of switch from depression into mania after therapeutic sleep deprivation in bipolar depression. Psychiatry Res. 86, 267-270. doi: $\quad 10.1016 / S 0165-1781(99)$ 00036-0

Cooper, J. C., and Knutson, B. (2008). Valence and salience contribute to nucleus accumbens activation. Neuroimage 39, 538-547. doi: 10.1016/j.neuroimage.2007.08.009

Dahan, L., Astier, B., Vautrelle, N., Urbain, N., Kocsis, B., and Chouvet, G. (2007). Prominent burst firing of dopaminergic neurons in the ventral tegmental area during paradoxical sleep. Neuropsychopharmacology 32, 1232-1241. doi 10.1038/sj.npp. 1301251

Dang-Vu, T. T., Schabus, M., Desseilles, M., Albouy, G., Boly, M., Darsaud, A., et al. (2008). Spontaneous neural activity during human slow wave sleep. Proc. Natl. Acad. Sci. U.S.A. 105, 15160-15165. doi: 10.1073/pnas.0801819105

Dang-Vu, T. T., Schabus, M., Desseilles, M., Sterpenich, V., Bonjean, M., and Maquet, P. (2010). Functional neuroimaging insights into the physiology of human sleep. Sleep 33, 1589-1603.

Danilenko, K. V., Cajochen, C., and Wirz-Justice, A. (2003). Is sleep per se a zeitgeber in humans? J. Biol. Rhythms 18, 170-178. doi: 10.1177/0748730403251732

Das, G., Gopalakrishnan, A. Faisal, M., and Mallick, B. N. (2008). Stimulatory role of calcium in rapid eye movement sleep deprivation-induced noradrenaline-mediated increase in Na-K-ATPase activity in rat brain. Neuroscience 155, 76-89. doi: 10.1016/j.neuroscience.2008.04.069

David, D., De Faria, L., Lapeyra, O., and Mellman, T. A. (2004). Adjunctive risperidone treatment in combat veterans with chronic PTSD. J. Clin. Psychopharmacol. 24, 556-559. doi: 10.1097/01.jcp.0000138771.46353.59

Der-Avakian, A., and Markou, A. (2012). The neurobiology of anhedonia and other reward-related deficits. Trends Neurosci. 35, 68-77. doi: 10.1016/j.tins.2011.11.005

Desseilles, M., Dang-Vu, T. T. Sterpenich, V., and Schwartz, S. (2011). Cognitive and emotional processes during dreaming: a neuroimaging view. Conscious. Cogn. 20, 998-1008. doi: 10.1016/j.concog.2010.10.005

Desseilles, M., Vu, T. D., Laureys, S., Peigneux, P., Degueldre, C., Phillips, C., et al. (2006). A prominent role for amygdaloid complexes in the Variability in Heart Rate (VHR) during Rapid Eye Movement (REM) sleep relative to wakefulness. Neuroimage 32, 1008-1015. doi: 10.1016/j.neuroimage.2006.06.008

Diekelmann, S., and Born, J. (2010). The memory function of sleep. Nat. Rev. Neurosci. 11, 114-126.

Diekelmann, S., Buchel, C., Born, J., and Rasch, B. (2011). Labile or stable: opposing consequences for memory when reactivated during waking and sleep. Nat. Neurosci. 14, 381-386. doi: 10.1038/nn.2744

Dinges, D. F., Pack, F., Williams, K., Gillen, K. A., Powell, J. W., Ott, G. E., et al. (1997). Cumulative sleepiness, mood disturbance, and psychomotor vigilance performance decrements during a week of sleep restricted to 4-5 hours per night. Sleep 20, 267-277.

Domhoff, G. (2011). The neural substrate for dreaming: is it a subsystem of the default network? Conscious. Cogn. 20, 1163-1174. doi: 10.1016/j.concog.2011.03.001

Doricchi, F., and Violani, C. (2000). Mesolimbic dopamine and the neuropsychology of dreaming: some caution and reconsiderations. Behav. Brain Sci. 23:6, 930-931. doi: 10.1017/S0140525X00374027

Ebert, D., and Berger, M. (1998). Neurobiological similarities in 
antidepressant sleep deprivation and psychostimulant use: a psychostimulant theory of antidepressant sleep deprivation. Psychopharmacology 140, 1-10. doi: 10.1007/s002130050732

Endo, T., Schwierin, B., Borbély, A., and Tobler, I. (1997). Selective and total sleep deprivation: effect on the sleep EEG in the rat. Psychiatry Res. 66, 97-110. doi: 10.1016/S01651781(96)03029-6

Ernst, M., and Paulus, M. P. (2005). Neurobiology of decision making: a selective review from a neurocognitive and clinical perspective. Biol. Psychiatry 58, 597-604. doi: 10.1016/j.biopsych.2005.06.004

Fischer, S., and Born, J. (2009). Anticipated reward enhances offline learning during sleep. J. Exp. Psychol. Learn. Mem. Cogn. 35, 1586-1593. doi: 10.1037/a0017256

Fogel, S. M., and Smith, C. T. (2011). The function of the sleep spindle: a physiological index of intelligence and a mechanism for sleep-dependent memory consolidation. Neurosci. Biobehav. Rev. 35, 1154-1165. doi: 10.1016/j.neubiorev.2010.12.003

Ford, D. E., and Kamerow, D. B. (1989). Epidemiologic study of sleep disturbances and psychiatric disorders. An opportunity for prevention? JAMA 262, 1479-1484. doi: 10.1001/jama.1989.03430110069030

Fortier-Brochu, E., Beaulieu-Bonneau, S., Ivers, H., and Morin, C. M. (2012). Insomnia and daytime cognitive performance: a meta-analysis. Sleep Med. Rev. 16, 83-94. doi: 10.1016/j.smrv.2011.03.008

Fosse, M. J., Fosse, R., Hobson, J. A., and Stickgold, R. J. (2003). Dreaming and episodic memory: a functional dissociation? J. Cogn. Neurosci. 15, 1-9. doi: 10.1162/089892903321107774

Fosse, R., Stickgold, R., and Hobson, J. A. (2004). Thinking and hallucinating: reciprocal changes in sleep. Psychophysiology 41, 298-305. doi: 10.1111/j.1469-8986.2003.00146.x

Gaillard, J. M., and Moneme, A. (1977). Modification of dream content after preferential blockade of mesolimbic and mesocortical dopaminergic systems. J. Psychiatr. Res. 13, 247-256. doi: 10.1016/S0022-3956 (77) $90020-6$

Giedke, H., and Schwarzler, F. (2002). Therapeutic use of sleep deprivation in depression. Sleep Med. Rev. 6, 361-377.

Giles, D. E., Kupfer, D. J., Rush, A. J., and Roffwarg, H. P. (1998). Controlled comparison of electrophysiological sleep in families of probands with unipolar depression. Am. J. Psychiatry 155, 192-199.

Gottesmann, C., and Gottesman, I. (2007). The neurobiological characteristics of rapid eye movement (REM) sleep are candidate endophenotypes of depression, schizophrenia, mental retardation and dementia. Prog. Neurobiol. 81, 237-250. doi: 10.1016/j.pneurobio.2007.01.004

Gujar, N., McDonald, S. A., Nishida, M., and Walker, M. P. (2011a). A role for REM sleep in recalibrating the sensitivity of the human brain to specific emotions. Cereb. Cortex 21, 115-123. doi: 10.1093/cercor/bhq064

Gujar, N., Yoo, S. S., Hu, P., and Walker, M. P. (2011b). Sleep deprivation amplifies reactivity of brain reward networks, biasing the appraisal of positive emotional experiences. J. Neurosci. 31, 4466-4474. doi: 10.1523/JNEUROSCI.3220-10.2011

Haber, S. N., and Knutson, B. (2010). The reward circuit: linking primate anatomy and human imaging. Neuropsychopharmacology 35, 4-26. doi: 10.1038/npp. 2009.129

Harris, G. C., Wimmer, M., and AstonJones, G. (2005). A role for lateral hypothalamic orexin neurons in reward seeking. Nature 437, 556-559. doi: 10.1038/nature04071

Harvey, A. G. (2008). Sleep and circadian rhythms in bipolar disorder: seeking synchrony, harmony, and regulation. Am. J. Psychiatry 165, 820-829. doi: 10.1176/appi.ajp.2008.08010098

Hasler, B. P., Buysse, D. J., Kupfer, D. J., and Germain, A. (2010). Phase relationships between core body temperature, melatonin, and sleep are associated with depression severity: further evidence for circadian misalignment in non-seasonal depression. Psychiatry Res. 178, 205-207. doi: $\quad 10.1016 /$ j.psychres.2010. 04.027

Hasler, B. P., and Clark, D. B. (2013). Circadian misalignment, rewardrelated brain function, and adolescent alcohol involvement. Alcohol. Clin. Exp. Res. 37, 558-565. doi: 10.1111/acer. 12003

Hobson, J. A. (2009). REM sleep and dreaming: towards a theory of protoconsciousness. Nat. Rev. Neurosci. $10,803-813$.

Hobson, J. A., and Friston, K. J. (2012). Waking and dreaming consciousness: Neurobiological and functional considerations. Prog. Neurobiol. 98, 82-98. doi: 10.1016/j.pneurobio.2012.05.003
Hobson, J. A., and Pace-Schott, E. F. (1999). Reply to solms, braun and reiser. Neuropsychoanalysis 1 , 206-224.

Hobson, J. A., Pace-Schott, E. F., and Stickgold, R. (2000). Dreaming and the brain: toward a cognitive neuroscience of conscious states. Behav. Brain Sci. 23, 793-842. discussion: 904-1121. doi: 10.1017/S0140525X00003976

Hobson, J. A., Pace-Schott, E. F., Stickgold, R., and Kahn, D. (1998). To dream or not to dream? Relevant data from new neuroimaging and electrophysiological studies. Curr. Opin. Neurobiol. 8, 239-244. doi: 10.1016/S0959-4388(98)80146-3

Holsboer, F. (2000). The corticosteroid receptor hypothesis of depression. Neuropsychopharmacology 23, 477-501. doi: 10.1016/S0893133X (00)00159-7

Home, J. (1988). Sleep loss and "divergent" thinking ability. Sleep 11 , 528-536.

Horikawa, T., Tamaki, M., Miyawaki, Y., and Kamitani, Y. (2013). Neural decoding of visual imagery during sleep. Science 340, 639-642. doi: $10.1126 /$ science. 1234330

Horovitz, S. G., Braun, A. R., Carr, W. S., Picchioni, D., Balkin, T. J., Fukunaga, M., et al. (2009). Decoupling of the brain's default mode network during deep sleep. Proc. Natl. Acad. Sci. U.S.A. 106, 11376-11381. doi: 10.1073/pnas.0901435106

Horovitz, S. G., Fukunaga, M., De Zwart, J. A., Van Gelderen, P. Fulton, S. C., Balkin, T. J., et al. (2008). Low frequency BOLD fluctuations during resting wakefulness and light sleep: a simultaneous EEG-fMRI study. Hum. Brain Mapp. 29, 671-682. doi: 10.1002/hbm.20428

Howell, M. J. (2012). Parasomnias: an updated review. Neurotherapeutics 9, 753-775. doi: 10.1007/s13311012-0143-8

Huber, R., Ghilardi, M. F., Massimini, M., and Tononi, G. (2004). Local sleep and learning. Nature 430, 78-81. doi: 10.1038 /nature02663

Inzelberg, R. (2013). The awakening of artistic creativity and parkinson's disease. Behav. Neurosci. 127, 256-261. doi: 10.1037/a0031052

Jackson, A., Cavanagh, J., and Scott, J. (2003). A systematic review of manic and depressive prodromes. J. Affect. Disord. 74, 209-217. doi: 10.1016/S0165-0327(02)00266-5

Jakovljevic, M., Sagud, M., and Mihaljevic-Peles, A. (2003). Olanzapine in the treatmentresistant, combat-related
PTSD-a series of case reports. Acta Psychiatr. Scand. 107, 394-396. discussion: 396. doi: 10.1034/j.1600-0447.2003.00065.x

Johnson, B. (2001). Drug dreams: a neuropsychoanalytic hypothesis. J. Am. Psychoanal. Assoc. 49, 75-96. doi: 10.1177/00030651010490011101

Johnson, E. O., Roth, T., and Breslau, N. (2006). The association of insomnia with anxiety disorders and depression: exploration of the direction of risk. J. Psychiatr. Res. 40, 700-708. doi: 10.1016/j.jpsychires.2006.07.008

Jouvet, M. (1999). The Paradox of Sleep: The Story of Dreaming. Cambridge: MIT Press.

Kahn, D., and Hobson, J. (2005). Theory of mind in dreaming: awareness of feelings and thoughts of others in dreams. Dreaming 15, 48-57. doi: 10.1037/1053-0797.15.1.48

Kamphuis, J., Meerlo, P., Koolhaas, J. M., and Lancel, M. (2012). Poor sleep as a potential causal factor in aggression and violence. Sleep Med. 13, 327-334. doi: 10.1016/j.sleep.2011.12.006

Killgore, W. D., Balkin, T. J. and Wesensten, N. J. (2006). Impaired decision making following $49 \mathrm{~h}$ of sleep deprivation. J. Sleep Res. 15, 7-13. doi: 10.1111/j.1365-2869.2006.00487.x

Killgore, W. D., Kahn-Greene, E. T., Lipizzi, E. L., Newman, R. A., Kamimori, G. H., and Balkin, T. J. (2008). Sleep deprivation reduces perceived emotional intelligence and constructive thinking skills. Sleep Med. 9, 517-526. doi: 10.1016/j.sleep.2007.07.003

Koike, T., Kan, S., Misaki, M., and Miyauchi, S. (2011). Connectivity pattern changes in default-mode network with deep non-REM and REM sleep. Neurosci. Res. 69, 322-330. doi: 10.1016/j.neures.2010.12.018

Kolla, B. P., and Auger, R. R. (2011). Jet lag and shift work sleep disorders: how to help reset the internal clock. Cleve. Clin. J. Med. 78, 675-684. doi: 10.3949/ccim.78a.10083

Koob, G. F. (2009). Dynamics of neuronal circuits in addiction: reward, antireward, and emotional memory. Pharmacopsychiatry 42 (Suppl. 1), S32-S41. doi: 10.1055/s-00291216356

Koob, G. F., and Volkow, N. D. (2010). Neurocircuitry of addiction. Neuropsychopharmacology 35, 217-238. doi: 10.1038/npp. 2009.110

Krebs, R. M., Heipertz, D., Schuetze, H., and Duzel, E. (2011). Novelty 
increases the mesolimbic functional connectivity of the substantia nigra/ventral tegmental area (SN/VTA) during reward anticipation: evidence from high-resolution fMRI. Neuroimage 58, 647-655. doi: 10.1016/j.neuroimage.2011.06.038

Lambert, M. T. (2006). Aripiprazole in the management of posttraumatic stress disorder symptoms in returning Global War on Terrorism veterans. Int. Clin. Psychopharmacol. 21, 185-187. doi: 10.1097/01.yic.0000185021.48279.00

Lansink, C. S., Goltstein, P. M., Lankelma, J. V., Joosten, R. N., McNaughton, B. L., and Pennartz, C. M. (2008). Preferential reactivation of motivationally relevant information in the ventral striatum. J. Neurosci. 28, 6372-6382. doi: 10.1523/JNEUROSCI.1054-08.2008

Lansink, C. S., Goltstein, P. M., Lankelma, J. V., McNaughton, B. L., and Pennartz, C. M. (2009). Hippocampus leads ventral striatum in replay of place-reward information. PLoS Biol. 7:e1000173. doi: 10.1371/journal.pbio.1000173

Lara-Carrasco, J., Nielsen, T. A., Solomonova, E., Levrier, K., and Popova, A. (2009). Overnight emotional adaptation to negative stimuli is altered by REM sleep deprivation and is correlated with intervening dream emotions. J. Sleep Res. 18, 178-187. doi: 10.1111/j.1365-2869.2008.00709.x

Larson-Prior, L. J., Zempel, J. M., Nolan, T. S., Prior, F. W., Snyder, A. Z., and Raichle, M. E. (2009). Cortical network functional connectivity in the descent to sleep. Proc. Natl. Acad. Sci. U.S.A. 106, 4489-4494. doi: 10.1073/pnas.0900924106

Laufs, H., Walker, M. C., and Lund, T. E. (2007). 'Brain activation and hypothalamic functional connectivity during human non-rapid eye movement sleep: an EEG/fMRI study'-its limitations and an alternative approach. Brain 130:e75; author reply e76.

Lena, I., Parrot, S., Deschaux, O., Muffat-Joly, S., Sauvinet, V., Renaud, B., et al. (2005). Variations in extracellular levels of dopamine, noradrenaline, glutamate, and aspartate across the sleep-wake cycle in the medial prefrontal cortex and nucleus accumbens of freely moving rats. J. Neurosci. Res. 81, 891-899. doi: 10.1002/ jnr.20602

Leverich, G. S., Altshuler, L. L., Frye, M. A., Suppes, T., McElroy, S. L., Keck, P. E., et al. (2006). Risk of switch in mood polarity to hypomania or mania in patients with bipolar depression during acute and continuation trials of venlafaxine, sertraline, and bupropion as adjuncts to mood stabilizers. Am. J. Psychiatry 163, 232-239. doi: 10.1176/appi.ajp. 163.2.232

Levin, R., and Nielsen, T. A. (2007). Disturbed dreaming, posttraumatic stress disorder, and affect distress: a review and neurocognitive model. Psychol. Bull. 133, 482-528. doi: 10.1037/0033-2909. 133.3.482

Li, J. Z., Bunney, B. G., Meng, F., Hagenauer, M. H., Walsh, D M., Vawter, M. P., et al. (2013). Circadian patterns of gene expression in the human brain and disruption in major depressive disorder. Proc. Natl. Acad. Sci. U.S.A. 110, 9950-9955. doi: 10.1073/pnas. 1305814110

Lisman, J. E., and Grace, A. A. (2005). The hippocampal-VTA loop: controlling the entry of information into long-term memory. Neuron 46, 703-713. doi: 10.1016/j.neuron.2005.05.002

Limb, C. J., and Braun, A. R. (2008). Neural substrates of spontaneous musical performance: an FMRI study of jazz improvisation. PLOS ONE 3:e1679. doi: 10.1371/journal.pone.0001679

Malcolm-Smith, S., Koopowitz, S., Pantelis, E., and Solms, M. (2012). Approach/avoidance in dreams. Conscious. Cogn. 21, 408-412. doi: 10.1016/j.concog.2011.11.004

Maloney, K. J., Mainville, L., and Jones, B. E. (2002). c-Fos expression in dopaminergic and GABAergic neurons of the ventral mesencephalic tegmentum after paradoxical sleep deprivation and recovery. Eur. J. Neurosci. 15, 774-778. doi: 10.1046/j.1460-9568.2002.01907.x

Maquet, P. (2001). The role of sleep in learning and memory. Science 294, 1048-1052. doi: 10.1126/science. 1062856

Maquet, P., Laureys, S., Peigneux, P., Fuchs, S., Petiau, C., Phillips, C., et al. (2000). Experiencedependent changes in cerebral activation during human REM sleep. Nat. Neurosci. 3, 831-836. doi: $10.1038 / 77744$

Maquet, P., Peters, J., Aerts, J., Delfiore, G., Degueldre, C., Luxen, A., et al. (1996). Functional neuroanatomy of human rapid-eye-movement sleep and dreaming. Nature 383, 163-166. doi: 10.1038/383163a0

Maquet, P., Ruby, P., Maudoux, A., Albouy, G., Sterpenich, V., Dang-Vu, T., et al. (2005). Human cognition during REM sleep and the activity profile within frontal and parietal cortices: a reappraisal of functional neuroimaging data. Prog. Brain Res. 150, 219-227. doi: $\quad 10.1016 / S 0079-6123(05)$ 50016-5

Maquet, P., Schwartz, S., Passingham, R., and Frith, C. (2003). Sleeprelated consolidation of a visuomotor skill: brain mechanisms as assessed by functional magnetic resonance imaging. J. Neurosci. 23, 1432-1440.

Marshall, L., Helgadottir, H., Molle, M., and Born, J. (2006). Boosting slow oscillations during sleep potentiates memory. Nature 444, 610-613. doi: $10.1038 /$ nature 05278

Mason, L., O'Sullivan, N., Blackburn, M., Bentall, R., and El-Deredy, W. (2012). I want it now! Neural correlates of hypersensitivity to immediate reward in hypomania. Biol. Psychiatry 71, 530-537. doi: 10.1016/j.biopsych.2011.10.008

Massimini, M., Ferrarelli, F., Huber, R., Esser, S. K., Singh, H., and Tononi, G. (2005). Breakdown of cortical effective connectivity during sleep. Science 309, 2228-2232. doi: 10.1126/science.1117256

Massimini, M., Ferrarelli, F., Murphy, M., Huber, R., Riedner, B., Casarotto, S., et al. (2010). Cortical reactivity and effective connectivity during REM sleep in humans. Cogn. Neurosci. 1, 176-183. doi 10.1080/17588921003731578

McNamara, P., Auerbach, S., Johnson, P., Harris, E., and Doros, G. (2010). Impact of REM sleep on distortions of self-concept, mood and memory in depressed/anxious participants. J. Affect. Disord. 122, 198-207. doi: 10.1016/j.jad.2009.06.030

McNamara, P., McLaren, D., Smith, D. Brown, A., and Stickgold, R. (2005). A "Jekyll and Hyde" within: aggressive versus friendly interactions in REM and non-REM dreams. Psychol. Sci. 16, 130-136. doi 10.1111/j.0956-7976.2005.00793.x

Menz, M. M., Buchel, C., and Peters, J. (2012). Sleep deprivation is associated with attenuated parametric valuation and control signals in the midbrain during value-based decision making. J. Neurosci. 32, 6937-6946. doi: 10.1523/JNEUROSCI.3553-11.2012

Merritt, J., Stickgold, R., Pace-Schott, E., and Hobson, J. (1994). Emotion profiles in the dreams of men and women. Conscious. Cogn. 3, 46-60. doi: 10.1006/ccog.1994.1004

Mileykovskiy, B. Y., Kiyashchenko, L. I., and Siegel, J. M. (2005). Behavioral correlates of activity in identified hypocretin/orexin neurons. Neuron 46, 787-798. doi: 10.1016/j.neuron.2005.04.035

Morgan, P. T., Pace-Schott, E. F., Sahul, Z. H., Coric, V., Stickgold, R., and Malison, R. T. (2006). Sleep, sleep-dependent procedural learning and vigilance in chronic cocaine users: evidence for occult insomnia. Drug Alcohol Depend. 82, 238-249. doi: 10.1016/j.drugalcdep. 2005.09.014

Morrison, A. R., Sanford, L. D., Ball, W. A., Mann, G. L., and Ross, R. J. (1995). Stimulus-elicited behavior in rapid eye movement sleep without atonia. Behav. Neurosci. 109, 972-979. doi: 10.1037/07357044.109.5.972

Morrissey, M. J., Duntley, S. P., Anch, A. M., and Nonneman, R. (2004). Active sleep and its role in the prevention of apoptosis in the developing brain. Med. Hypotheses 62, 876-879. doi: 10.1016/j.mehy.2004.01.014

Nielsen, T., Deslauriers, D., and Baylor, G. (1991). Emotions in dream and waking event reports. Dreaming 1, 287-300. doi: 10.1037/h0094340

Nielsen, T., and Levin, R. (2007). Nightmares: a new neurocognitive model. Sleep Med. Rev. 11, 295-310. doi: 10.1016/j.smrv.2007.03.004

Nofzinger, E. A., Buysse, D. J., Miewald, J. M., Meltzer, C. C., Price, J. C., Sembrat, R. C., et al. (2002). Human regional cerebral glucose metabolism during non-rapid eye movement sleep in relation to waking. Brain 125, 1105-1115. doi: 10.1093/brain/awf103

Nofzinger, E. A., Mintun, M. A. Wiseman, M., Kupfer, D. J., and Moore, R. Y. (1997). Forebrain activation in REM sleep: an FDG PET study. Brain Res. 770, 192-201. doi: 10.1016/S0006-8993(97)00807-X

Nofzinger, E. A., Reynolds, C. F. 3rd., Thase, M. E., Frank, E., Jennings, J. R., Fasiczka, A. L., et al. (1995). REM sleep enhancement by bupropion in depressed men. Am. J. Psychiatry 152, 274-276.

Ohayon, M. M., and Roth, T. (2003). Place of chronic insomnia in the course of depressive and anxiety disorders. J. Psychiatr. Res. 37, 9-15. doi: 10.1016/S0022-3956 (02)00052-3

Opp, M. R. (2009). Sleeping to fuel the immune system: mammalian sleep and resistance to parasites. BMC Evol. Biol. 9:8. doi: 10.1186/14712148-9-8

Ott, G. E., Rao, U., Lin, K. M., Gertsik, L., and Poland, R. E. (2004). Effect of treatment with bupropion on EEG sleep: relationship to antidepressant response. Int. J. 
Neuropsychopharmacol. 7, 275-281. doi: 10.1017/S1461145704004298

Oudiette, D., Constantinescu, I., Leclair-Visonneau, L., Vidailhet, M., Schwartz, S., and Arnulf, I. (2011). Evidence for the re-enactment of a recently learned behavior during sleepwalking. PLoS ONE 6:e18056. doi: 10.1371/journal.pone.0018056

Oudiette, D., De Cock, V. C., Lavault, S., Leu, S., Vidailhet, M., and Arnulf, I. (2009). Nonviolent elaborate behaviors may also occur in REM sleep behavior disorder. Neurology 72, 551-557. doi: 10.1212/01.wnl.0000341936. $78678.3 \mathrm{a}$

Oudiette, D., and Paller, K. A. (2013). Upgrading the sleeping brain with targeted memory reactivation. Trends Cogn. Sci. 17, 142-149. doi: 10.1016/j.tics.2013.01.006

Pace-Schott, E. (2001). Theory of mind, social cognition and dreaming. Sleep Res. Soc. Bull. 7, 33-36.

Pace-Schott, E. F. (2011). "The neurobiology of dreaming," in Principles and Practice of Sleep Medicine, 5th Edn., eds M. H. Kryger, T. Roth, and W. C. Dement (Philadelphia, PA: Elsevier), 563-575. doi: 10.1016/B978-14160-6645-3.00048-7

Pace-Schott, E. F. (2007). The Frontal Lobes and Dreaming. Westport: Praeger Publishers.

Pace-Schott, E. F. (2013). Dreaming as a story-telling instinct. Front. Psychol. 4:159. doi: 10.3389/fpsyg.2013.00159

Pace-Schott, E. F., Milad, M. R., Orr, S. P., Rauch, S. L., Stickgold, R., and Pitman, R. K. (2009). Sleep promotes generalization of extinction of conditioned fear. Sleep 32, 19-26.

Pace-Schott, E. F., Nave, G., Morgan, A., and Spencer, R. M. (2012a). Sleepdependent modulation of affectively guided decision-making. J. Sleep Res. 21, 30-39. doi: 10.1111/j.13652869.2011.00921.x

Pace-Schott, E. F., Verga, P. W., Bennett, T. S., and Spencer, R. M. (2012b). Sleep promotes consolidation and generalization of extinction learning in simulated exposure therapy for spider fear. J. Psychiatr. Res. 46, 1036-1044. doi: 10.1016/j.jpsychires.2012.04.015

Pace-Schott, E. F., Shepherd, E., Spencer, R. M., Marcello, M., Tucker, M., Propper, R. E., et al. (2011). Napping promotes inter-session habituation to emotional stimuli. Neurobiol. Learn. Mem. 95, 24-36. doi: 10.1016/j.nlm.2010.10.006

Panksepp, J. (1998). Affective Neuroscience: the Foundations of Human and Animal Emotions. New York, NY: Oxford University Press.

Payne, J. D., and Kensinger, E. A. (2010). Sleep leads to changes in the emotional memory trace: evidence from fMRI. J. Cogn. Neurosci. 23, 1285-1297. doi: 10.1162/jocn.2010.21526

Payne, J. D., and Kensinger, E. A. (2011). Sleep leads to changes in the emotional memory trace: evidence from FMRI. J. Cogn. Neurosci. 23, 1285-1297. doi: $10.1162 /$ jocn.2010.21526

Payne, J. L., Quiroz, J. A., Zarate, C. A., and Manji, H. K. (2002). Timing is everything: does the robust upregulation of noradrenergically regulated plasticity genes underlie the rapid antidepressant effects of sleep deprivation? Biol. Psychiatry 52, 921-926. doi: 10.1016/S0006-3223(02)01676-1

Peigneux, P., Laureys, S., Fuchs, S., Collette, F., Perrin, F., Reggers, J., et al. (2004). Are spatial memories strengthened in the human hippocampus during slow wave sleep? Neuron 44, 535-545. doi: 10.1016/j.neuron.2004.10.007

Pennartz, C. M., Ito, R., Verschure, P. F., Battaglia, F. P., and Robbins, T. W. (2011). The hippocampalstriatal axis in learning, prediction and goal-directed behavior. Trends Neurosci. 34, 548-559. doi: 10.1016/j.tins.2011.08.001

Pennartz, C. M., Lee, E., Verheul, J., Lipa, P., Barnes, C. A., and McNaughton, B. L. (2004). The ventral striatum in off-line processing: ensemble reactivation during sleep and modulation by hippocampal ripples. J. Neurosci. 24, 6446-6456. doi: 10.1523/JNEUROSCI.0575-04.2004

Perlis, L., and Nielsen, T. (1993). Mood regulation, dreaming and nightmares: evaluation of a desensitization function. Dreaming 3, 243-257. doi: $10.1037 / h 0094383$

Perogamvros, L. (2013). Consciousness and the invention of Morel. Front. Hum. Neurosci. 7:61. doi: 10.3389/fnhum.2013.00061

Perogamvros, L., Baud, P., Hasler, R., Cloninger, C. R., Schwartz, S., and Perrig, S. (2012). Active reward processing during human sleep: insights from sleep-related eating disorder. Front. Neurol. 3:168. doi: 10.3389/fneur.2012.00168

Perogamvros, L., and Schwartz, S. (2012). The roles of the reward system in sleep and dreaming. Neurosci. Biobehav. Rev. 36, 1934-1951. doi: 10.1016/j.neubiorev.2012.05.010
Perry, E. K., and Piggott, M. A. (2000). Neurotransmitter mechanisms of dreaming: implication of modulatory systems based on dream intensity. Behav. Brain Sci. 23, 990-992. doi: 10.1017/S0140525X00774024

Pinter, M. M., Pogarell, O., and Oertel, W. H. (1999). Efficacy, safety, and tolerance of the non-ergoline dopamine agonist pramipexole in the treatment of advanced Parkinson's disease: a double blind, placebo controlled, randomised, multicentre study. J. Neurol. Neurosurg. Psychiatr. 66, 436-441. doi: 10.1136/jnnp.66.4.436

Pizzagalli, D. A., Holmes, A. J., Dillon, D. G., Goetz, E. L., Birk, J. L., Bogdan, R., et al. (2009). Reduced caudate and nucleus accumbens response to rewards in unmedicated individuals with major depressive disorder. Am. J. Psychiatry 166, 702-710. doi 10.1176/appi.ajp.2008.08081201

Plante, D. T., Jensen, J. E., Schoerning, L., and Winkelman, J. W. (2012). Reduced gamma-aminobutyric acid in occipital and anterior cingulate cortices in primary insomnia: a link to major depressive disorder? Neuropsychopharmacology 37, 1548-1557. doi: 10.1038/npp. 2012.4

Plante, D. T., and Winkelman, J. W. (2008). Sleep disturbance in bipolar disorder: therapeutic implications. Am. J. Psychiatry 165, 830-843. doi: 10.1176/appi.ajp. 2008.08010077

Ponz, A., Khatami, R., Poryazova, R., Werth, E., Boesiger, P., Bassetti, C. L., et al. (2010a). Abnormal activity in reward brain circuits in human narcolepsy with cataplexy. Ann. Neurol. 67, 190-200. doi: 10.1002/ana.21825

Ponz, A., Khatami, R., Poryazova, R., Werth, E., Boesiger, P., Schwartz, S., et al. (2010b). Reduced amygdala activity during aversive conditioning in human narcolepsy. Ann. Neurol. 67, 394-398.

Popa, D., Duvarci, S., Popescu, A. T., Lena, C., and Pare, D. (2010). Coherent amygdalocortical theta promotes fear memory consolidation during paradoxical sleep. Proc. Natl. Acad. Sci. U.S.A. 107, 6516-6519. doi: 10.1073/pnas.0913016107

Provini, F., Vetrugno, R., and Montagna, P. (2008). Sleeprelated smoking syndrome. Sleep Med. 9, 903-905. doi 10.1016/j.sleep.2007.10.021

Puhl, M. D., Fang, J., and Grigson, P. S. (2009). Acute sleep deprivation increases the rate and efficiency of cocaine self-administration, but not the perceived value of cocaine reward in rats. Pharmacol. Biochem. Behav. 94, 262-270. doi: 10.1016/j.pbb.2009.09.005

Rasch, B., Buchel, C., Gais, S., and Born, J. (2007). Odor cues during slow-wave sleep prompt declarative memory consolidation. Science 315, 1426-1429. doi: 10.1126/science.1138581

Ravassard, P., Pachoud, B., Comte, J. C., Mejia-Perez, C., Scote-Blachon, C., Gay, N., et al. (2009). Paradoxical (REM) sleep deprivation causes a large and rapidly reversible decrease in long-term potentiation, synaptic transmission, glutamate receptor protein levels, and ERK/MAPK activation in the dorsal hippocampus. Sleep 32, 227-240.

Rechtschaffen, A., and Bergmann, B. M. (2001). Sleep deprivation and host defense. Am. J. Physiol. Regul. Integr. Comp. Physiol. 280, R602-R603.

Redgrave, P., Prescott, T. J., and Gurney, K. (1999). Is the shortlatency dopamine response too short to signal reward error? Trends Neurosci. 22, 146-151. doi: 10.1016/S0166-2236(98)01373-3

Revonsuo, A. (2000). The reinterpretation of dreams: an evolutionary hypothesis of the function of dreaming. Behav. Brain Sci. 23, 877-901. discussion: 904-1121. doi: 10.1017/S0140525X00004015

Ribeiro, S., Mello, C. V., Velho, T., Gardner, T. J., Jarvis, E. D., and Pavlides, C. (2002). Induction of hippocampal long-term potentiation during waking leads to increased extrahippocampal zif-268 expression during ensuing rapideye-movement sleep. J. Neurosci. 22, 10914-10923.

Ribeiro, S., and Nicolelis, M. A. (2004) Reverberation, storage, and postsynaptic propagation of memories during sleep. Learn. Mem. 11, 686-696. doi: 10.1101/lm.75604

Richardson, C. L., Tate, W. P., Mason, S. E., Lawlor, P. A., Dragunow, M., and Abraham, W. C. (1992). Correlation between the induction of an immediate early gene, zif/268, and long-term potentiation in the dentate gyrus. Brain Res. 580, 147-154. doi: $\quad 10.1016 / 0006-8993(92)$ 90938-6

Riemann, D., and Voderholzer, U. (2003). Primary insomnia: a risk factor to develop depression? J. Affect. Disord. 76, 255-259. doi: 10.1016/S0165-0327(02)00072-1

Riemann, D., Voderholzer, U., and Berger, M. (2002). Sleep and sleepwake manipulations in bipolar 
depression. Neuropsychobiology 45(Suppl. 1), 7-12. doi: 10.1159/000049255

Riemann, D., Voderholzer, U., Spiegelhalder, K., Hornyak, M., Buysse, D. J., Nissen, C., et al. (2007). Chronic insomnia and MRI-measured hippocampal volumes: a pilot study. Sleep 30, 955-958.

Roane, B. M., and Taylor, D. J. (2008). Adolescent insomnia as a risk factor for early adult depression and substance abuse. Sleep 31, 1351-1356.

Rosanova, M., and Ulrich, D. (2005). Pattern-specific associative longterm potentiation induced by a sleep spindle-related spike train. J. Neurosci. 25, 9398-9405. doi: 10.1523/JNEUROSCI.2149-05.2005

Roybal, K., Theobold, D., Graham, A., Dinieri, J. A., Russo, S. J., Krishnan, V., et al. (2007). Manialike behavior induced by disruption of CLOCK. Proc. Natl. Acad. Sci. U.S.A. 104, 6406-6411. doi: 10.1073/pnas.0609625104

Rubinsztein, J. S., Fletcher, P. C., Rogers, R. D., Ho, L. W., Aigbirhio, F. I., Paykel, E. S., et al. (2001). Decision-making in mania: a PET study. Brain 124, 2550-2563. doi: 10.1093/brain/124.12.2550

Rudoy, J. D., Voss, J. L., Westerberg, C. E., and Paller, K. A. (2009). Strengthening individual memories by reactivating them during sleep. Science 326, 1079. doi: 10.1126/science. 1179013

Salvadore, G., Quiroz, J. A., MachadoVieira, R., Henter, I. D., Manji, H. K., and Zarate, C. A. Jr. (2010). The neurobiology of the switch process in bipolar disorder: a review. J. Clin. Psychiatry 71, 1488-1501. doi: 10.4088/JCP.09r05259gre

Samann, P. G., Wehrle, R., Hoehn, D., Spoormaker, V. I., Peters, H., Tully, C., et al. (2011). Development of the brain's default mode network from wakefulness to slow wave sleep. Cereb. Cortex 21, 2082-2093. doi: 10.1093/cercor/bhq295

Schabus, M., Dang-Vu, T. T., Albouy, G., Balteau, E., Boly, M., Carrier, J., et al. (2007). Hemodynamic cerebral correlates of sleep spindles during human non-rapid eye movement sleep. Proc. Natl. Acad. Sci. U.S.A. 104, 13164-13169. doi: 10.1073/pnas.0703084104

Schenck, C. H., and Mahowald, M. W. (2002). REM sleep behavior disorder: clinical, developmental, and neuroscience perspectives 16 years after its formal identification in sleep. Sleep 25, 120-138.

Schmider, J., Lammers, C. H., Gotthardt, U., Dettling, M.,
Holsboer, F., and Heuser, I. J. (1995). Combined dexamethasone/corticotropinreleasing hormone test in acute and remitted manic patients, in acute depression, and in normal controls: I. Biol. Psychiatry 38, 797-802. doi: 10.1016/0006-3223(95)00064-X

Schredl, M., Berger, M., and Riemann, D. (2009). The effect of trimipramine on dream recall and dream emotions in depressive outpatients. Psychiatry Res. 167, 279-286. doi: 10.1016/j.psychres.2008.03.002

Schredl, M., and Hofmann, F. (2003). Continuity between waking activities and dream activities. Conscious. Cogn. 12, 298-308. doi: 10.1016/S1053-8100(02)00072-7

Schultz, W. (1997). Dopamine neurons and their role in reward mechanisms. Curr. Opin. Neurobiol. 7, 191-197. doi: 10.1016/S09594388(97)80007-4

Schultz, W. (2002). Getting formal with dopamine and reward. Neuron 36, 241-263. doi: 10.1016/S08966273(02)00967-4

Schultz, W. (2010a). Dopamine signals for reward value and risk: basic and recent data. Behav. Brain Funct. 6:24. doi: 10.1186/1744-9081-6-24

Schultz, W. (2010b). Subjective neuronal coding of reward: temporal value discounting and risk. Eur. J. Neurosci. 31, 2124-2135. doi: 10.1111/j.1460-9568.2010.07282.x

Schultz, W., and Dickinson, A. (2000). Neuronal coding of prediction errors. Аnnu. Rev. Neurosci. 23, 473-500. doi: 10.1146/annurev.neuro.23.1.473

Schwartz, S. (2003). Are life episodes replayed during dreaming? Trends Cogn. Sci. 7, 325-327. doi: 10.1016/S1364-6613(03)00162-1

Schwartz, S. (2004). What dreaming can reveal about cognitive and brain functions during sleep: a lexicostatistical analysis of dream reports. Psychol. Belg. 44, 5-42.

Schwartz, S., and Maquet, P. (2002). Sleep imaging and the neuropsychological assessment of dreams. Trends Cogn. Sci. 6, 23-30. doi: 10.1016/S1364-6613(00)01818-0

Schwartz, S., Maquet, P., and Frith, C. (2002). Neural correlates of perceptual learning: a functional MRI study of visual texture discrimination. Proc. Natl. Acad. Sci. U.S.A. 99, 17137-17142. doi: 10.1073/pnas.242414599

Schwartz, S., Ponz, A., Poryazova, R., Werth, E., Boesiger, P., Khatami, R., et al. (2008). Abnormal activity in hypothalamus and amygdala during humour processing in human narcolepsy with cataplexy. Brain 131, 514-522. doi: 10.1093/brain/awm292

Shaffery, J. P., Sinton, C. M., Bissette, G., Roffwarg, H. P., and Marks, G. A. (2002). Rapid eye movement sleep deprivation modifies expression of long-term potentiation in visual cortex of immature rats. Neuroscience 110, 431-443. doi 10.1016/S0306-4522(01)00589-9

Shapiro, C. M., Trajanovic, N. N., and Fedoroff, J. P. (2003). Sexsomnia-a new parasomnia? Can J. Psychiatry $48,311-317$.

Shohamy, D., and Adcock, R. A. (2010). Dopamine and adaptive memory. Trends Cogn. Sci. 14, 464-472. doi: 10.1016/j.tics.2010.08.002

Singer, A. C., and Frank, L. M. (2009). Rewarded outcomes enhance reactivation of experience in the hippocampus. Neuron 64, 910-921. doi: 10.1016/j.neuron.2009.11.016

Smith, M. R., Antrobus, J. S., Gordon, E., Tucker, M. A., Hirota, Y., Wamsley, E. J., et al. (2004). Motivation and affect in REM sleep and the mentation reporting process. Conscious. Cogn. 13, 501-511. doi: 10.1016/j.concog.2004.03.002

Solms, M. (1997). The Neuropsychology of Dreams: A Clinico-Anatomical Study. New Jersey, NJ: Lawrence Erlbaum Associates.

Solms, M. (2000). Dreaming and REM sleep are controlled by different brain mechanisms. Behav. Brain Sci. 23, 843-850. discussion: 904-1121. doi: $10.1017 / S 0140525 X 00003988$

Spiegel, K., Leproult, R., and Van Cauter, E. (1999). Impact of sleep debt on metabolic and endocrine function. Lancet 354, 1435-1439. doi: 10.1016/S01406736(99)01376-8

Staner, L. (2010). Comorbidity of insomnia and depression. Sleep Med. Rev. 14, 35-46. doi: 10.1016/j.smrv.2009.09.003

Sterpenich, V., Albouy, G., Boly, M., Vandewalle, G., Darsaud, A., Balteau, E., et al. (2007) Sleep-related hippocampo-cortical interplay during emotional memory recollection. PLoS Biol. 5:e282. doi: 10.1371/journal.pbio.0050282

Sterpenich, V., Albouy, G., Darsaud, A., Schmidt, C., Vandewalle, G., Dang Vu, T. T., et al. (2009). Sleep promotes the neural reorganization of remote emotional memory. J. Neurosci. 29, 5143-5152. doi: 10.1523/JNEURO SCI.0561-09.2009

Stickgold, R. (2005). Sleepdependent memory consolidation. Nature 437, 1272-1278. doi: 10.1038/nature04286
Stickgold, R., Scott, L., Rittenhouse, C., and Hobson, J. A. (1999). Sleep-induced changes in associative memory. J. Cogn. Neurosci. 11, 182-193. doi: 10.1162/089892999563319

Stickgold, R., and Walker, M. P. (2007). Sleep-dependent memory consolidation and reconsolidation. Sleep Med. 8, 331-343. doi: 10.1016/j.sleep.2007.03.011

Takahashi, K., Lin, J. S., and Sakai, K. (2008). Neuronal activity of orexin and non-orexin waking-active neurons during wake-sleep states in the mouse. Neuroscience 153, 860-870. doi 10.1016/j.neuroscience.2008.02.058

Takenouchi, K., Nishijo, H., Uwano, T., Tamura, R., Takigawa, M., and Ono, T. (1999). Emotional and behavioral correlates of the anterior cingulate cortex during associative learning in rats. Neuroscience 93, 1271-1287. doi: 10.1016/S03064522(99)00216-X

Talamini, L. M., Bringmann, L. F., De Boer, M., and Hofman, W. F. (2013). Sleeping worries away or worrying away sleep? Physiological evidence on sleep-emotion interactions. PLoS ONE 8:e62480. doi: 10.1371/journal.pone. 0062480

Tassinari, C. A., Rubboli, G., Gardella, E., Cantalupo, G., CalandraBuonaura, G., Vedovello, M., et al. (2005). Central pattern generators for a common semiology in frontolimbic seizures and in parasomnias. A neuroethologic approach. Neurol. Sci. 26(Suppl. 3), S225-S232. doi: 10.1007/s10072-005-0492-8

Telzer, E. H., Fuligni, A. J., Lieberman, M. D., and Galvan, A. (2013). The effects of poor quality sleep on brain function and risk taking in adolescence. Neuroimage 71, 275-283. doi: 10.1016/j.neuroimage.2013.01.025

Thompson, D. F., and Pierce, D. R. (1999). Drug-induced nightmares. Ann. Pharmacother. 33, 93-98. doi: 10.1345/aph. 18150

Thompson, J. L., and Borgland, S. L. (2011). A role for hypocretin/orexin in motivation. Behav. Brain Res. 217, 446-453. doi: 10.1016/j.bbr.2010.09.028

Tremblay, L. K., Naranjo, C. A. Graham, S. J., Herrmann, N., Mayberg, H. S., Hevenor, S., et al. (2005). Functional neuroanatomical substrates of altered reward processing in major depressive disorder revealed by a dopaminergic probe. Arch. Gen. Psychiatry 62, 1228-1236. doi: 10.1001/archpsyc.62.11.1228

Tucker, M. A., Tang, S. X., Uzoh, A., Morgan, A., and Stickgold, R. 
(2011). To sleep, to strive, or both: how best to optimize memory. PLoS ONE 6:e21737. doi: 10.1371/journal.pone.0021737

Tufik, S., Troncone, L. R., Braz, S., Silva-Filho, A. R., and Neumann, B. G. (1987). Does REM sleep deprivation induce subsensitivity of presynaptic dopamine or postsynaptic acetylcholine receptors in the rat brain? Eur. J. Pharmacol. 140, 215-219. doi: 10.1016/ 0014-2999(87)90808-9

Van Cauter, E., Spiegel, K., Tasali, E., and Leproult, R. (2008). Metabolic consequences of sleep and sleep loss. Sleep Med. 9(Suppl. 1), S23-S28. doi: 10.1016/S1389-9457 (08)70013-3

Van Der Helm, E., Yao, J., Dutt, S., Rao, V., Saletin, J. M., and Walker, M. P. (2011). REM sleep depotentiates amygdala activity to previous emotional experiences. Curr. Biol. 21, 2029-2032. doi: 10.1016/j.cub.2011.10.052

Van Dongen, H. P., Maislin, G., Mullington, J. M., and Dinges, D. F. (2003). The cumulative cost of additional wakefulness: doseresponse effects on neurobehavioral functions and sleep physiology from chronic sleep restriction and total sleep deprivation. Sleep 26, 117-126.

Vandekerckhove, M., and Cluydts, R. (2010). The emotional brain and sleep: an intimate relationship. Sleep Med. Rev. 14, 219-226. doi: 10.1016/j.smrv.2010.01.002

Venkatraman, V., Chuah, Y. M., Huettel, S. A., and Chee, M. W. (2007). Sleep deprivation elevates expectation of gains and attenuates response to losses following risky decisions. Sleep 30, 603-609.

Vetrugno, R., Manconi, M., FeriniStrambi, L., Provini, F., Plazzi, G., and Montagna, P. (2006). Nocturnal eating: sleep-related eating disorder or night eating syndrome? A videopolysomnographic study. Sleep 29, 949-954.

Wagner, U., Fischer, S., and Born, J. (2002). Changes in emotional responses to aversive pictures across periods rich in slowwave sleep versus rapid eye movement sleep. Psychosom. Med. 64, 627-634. doi: 10.1097/ 01.PSY.0000021940.35402.51

Wagner, U., Gais, S., and Born, J. (2001). Emotional memory formation is enhanced across sleep intervals with high amounts of rapid eye movement sleep. Learn. Mem. 8, 112-119. doi: 10.1101/lm.36801

Wagner, U., Gais, S., Haider, H., Verleger, R., and Born, J. (2004). Sleep inspires insight. Nature 427, 352-355. doi: 10.1038/nature02223

Walker, M. P., Brakefield, T., Morgan, A., Hobson, J. A., and Stickgold, R. (2002a). Practice with sleep makes perfect: sleep-dependent motor skill learning. Neuron 35, 205-211. doi: 10.1016/S0896-6273(02)00746-8

Walker, M. P., Liston, C., Hobson, J. A., and Stickgold, R. (2002b). Cognitive flexibility across the sleep-wake cycle: REM-sleep enhancement of anagram problem solving. Brain Res. Cogn. Brain Res. 14, 317-324. doi: 10.1016/S0926-6410(02)00134-9

Walker, M. P., and Van Der Helm, E. (2009). Overnight therapy? The role of sleep in emotional brain processing. Psychol. Bull. 135, 731-748. doi: 10.1037/a0016570

Wamsley, E. J., Hirota, Y., Tucker, M. A., Smith, M. R., and Antrobus, J. S. (2007a). Circadian and ultradian influences on dreaming: a dual rhythm model. Brain Res. Bull. 71, 347-354. doi: 10.1016/j.brainresbull.2006.09.021

Wamsley, E. J., Hirota, Y., Tucker, M. A., Smith, M. R., and Antrobus, J. S. (2007b). Circadian and ultradian influences on dreaming: a dual rhythm model. Brain Res. Bull. 71, 347-354. doi: 10.1016/j.brainresbull.2006.09.021

Wamsley, E. J., Tucker, M., Payne, J. D., Benavides, J. A., and Stickgold, R. (2010). Dreaming of a learning task is associated with enhanced sleep-dependent memory consolidation. Curr. Biol. 20, 850-855. doi: 10.1016/j.cub. 2010.03 .027
Wang, S. H., and Morris, R. G. (2010). Hippocampal-neocortical interactions in memory formation, consolidation, and reconsolidation. Annu. Rev. Psychol. 61, 49-79, C41-C44.

Wehr, T., and Wirz-Justice, A. (1981) Internal Coincidence Model for Sleep Deprivation and Depression. Basel: Karger.

Wehr, T. A. (1991). Sleep-loss as a possible mediator of diverse causes of mania. Br. J. Psychiatry 159, 576-578. doi: 10.1192/bjp.159.4.576

Wehr, T. A., Goodwin, F. K., WirzJustice, A., Breitmaier, J., and Craig, C. (1982). 48-hour sleepwake cycles in manic-depressive illness: naturalistic observations and sleep deprivation experiments. Arch. Gen. Psychiatry 39, 559-565. doi: 10.1001/archpsyc. 1982.04290050037008

Wehr, T. A., Sack, D. A., and Rosenthal, N. E. (1987). Sleep reduction as a final common pathway in the genesis of mania. Am. J. Psychiatry 144, 201-204.

Wilhelm, I., Diekelmann, S., Molzow, I., Ayoub, A., Molle, M., and Born, J. (2011). Sleep selectively enhances memory expected to be of future relevance. J. Neurosci. 31, 1563-1569. doi: 10.1523/JNEUROSCI.3575-10.2011

Winkelman, J. W. (2006). Sleep-related eating disorder and night eating syndrome: sleep disorders, eating disorders, or both? Sleep 29 876-877.

Winson, J. (1972). Interspecies differences in the occurrence of theta. Behav. Biol. 7, 479-487. doi: 10.1016/S0091-6773(72)80210-4

Wirz-Justice, A. (2003). Chronobiology and mood disorders. Dialogues Clin. Neurosci. 5, 315-325.

Wittmann, B. C., Bunzeck, N., Dolan, R. J., and Duzel, E. (2007). Anticipation of novelty recruits reward system and hippocampus while promoting recollection. Neuroimage 38, 194-202. doi: 10.1016/j.neuroimage.2007.06.038

Wong, M. M., Brower, K. J., and Zucker, R. A. (2009). Childhood sleep problems, early onset of substance use and behavioral problems in adolescence. Sleep Med. 10, 787-796. doi: 10.1016/j.sleep.2008.06.015

Wurts, S. W., and Edgar, D. M. (2000). Circadian and homeostatic control of rapid eye movement (REM) sleep: promotion of REM tendency by the suprachiasmatic nucleus. $J$. Neurosci. 20, 4300-4310.

Yoo, S. S., Gujar, N., Hu, P., Jolesz, F. A., and Walker, M. P. (2007). The human emotional brain without sleep-a prefrontal amygdala disconnect. Curr. Biol. 17, R877-R878. doi: 10.1016 j.cub.2007.08.007

Zadra, A. (1996). Recurrent Dreams: Their Relation to Life Events. Cambridge: Harvard University Press.

Zohar, D., Tzischinsky, O., Epstein, R., and Lavie, P. (2005). The effects of sleep loss on medical residents' emotional reactions to work events: a cognitive-energy model. Sleep 28, 47-54.

Conflict of Interest Statement: The authors declare that the research was conducted in the absence of any commercial or financial relationships that could be construed as a potential conflict of interest.

Received: 27 March 2013; accepted: 06 July 2013; published online: 25 July 2013. Citation: Perogamvros L, Dang-Vu TT, Desseilles M and Schwartz S (2013) Sleep and dreaming are for important matters. Front. Psychol. 4:474. doi: 10.3389/fpsyg. 2013.00474

This article was submitted to Frontiers in Consciousness Research, a specialty of Frontiers in Psychology.

Copyright (c) 2013 Perogamvros, Dang$V u$, Desseilles and Schwartz. This is an open-access article distributed under the terms of the Creative Commons Attribution License, which permits use, distribution and reproduction in other forums, provided the original authors and source are credited and subject to any copyright notices concerning any thirdparty graphics etc. 